\title{
The Environmental Impact Evaluation and Testing of Sustainable Inorganic Binders: A Green Alternative to Ordinary Portland Cement
}

\author{
Beste Cubukcuoglu, ${ }^{1, *}$ \\ ${ }^{1}$ Department of Civil Engineering, Faculty of Engineering and \\ Architecture Bahcesehir Cyprus University BAU Tower, Nicosia, Cyprus
}

Received February 13, 2018; accepted April 11, 2018

\begin{abstract}
Sustainable alternative constituents to cement are required to reduce its detrimental impact on the environment. This study mainly focuses on the alternative materials to cement which are all derived as by-products from steel/iron and $\mathrm{MgO}$ manufacturing industry. These alternative materials have been popularised in the last few years for their effective usage in the environmental applications. Furnace steel slag, low grade $\mathrm{MgO}$ and pulverised fly ash are the materials proposed as cement replacement. The results of this study will be used to demonstrate the characteristics of alternative materials by means of both physical and chemical.
\end{abstract}

Keywords: cement, Pulverised fuel ash, Magnesium Oxide, sustainable construction materials, environmental applications

\section{Introduction}

The concept of sustainability has been growing in popularity since many years. In parallel to this popularity, the use of sustainable construction materials mostly in construction industry and in many environmental applications has been preferred. Cement is the most commonly used construction materials with very high carbon emissions. The production of cement causes large amounts of carbon emissions to be released into the environment and involves an overuse of natural resources [1]. Therefore, more environmental friendly alternatives to cement are being sought. This has incited the use of different types of additives and binders as substitutes for cement.

An industrial by-product may be used in the cement manufacturing process in two different ways. One could be the use of the by-product as the raw material feed to the kiln in the manufacture of PC in place of coal. Alternatively, by-products could be used together with PC by mixing slag cements or PFA as pozzolans [2], [3]. Moreover, cement/fly ash, cement/soluble silicate and lime/coal fly ash are the combinations that have been tried for the replacement of cement [4].

In this paper, alternative binding agents to cement are discussed in detail with the aim of achieving the most sustainable way of producing cement or its substitutes with same or at least similar mechanical and chemical properties. Accordingly, LGMgO is found to be an effective cement replacement material at different ratios. LGMgO has similar hydration characteristics as cement. Strength development continues at longer curing ages and LGMgO is reactive enough when in contact with water to produce

\footnotetext{
* Corresponding author:

E-mail: beste.cubukcuoglu@ cyprus.bau.edu.tr (B. Cubukuglu)
} 
hydration reactions and products that are required for strength development. The compressive strength development of LGMgO is not as good as cement however it is promising that these materials can replace cement in many other civil engineering and/or environmental applications. The findings highlighted the environmental and economic potential of replacing cement and other binding materials with $\mathrm{LGMgO}$ and steel slag. The replacement materials should also be as cost-effective as cement. The cost of the binders may cause severe restrictions on what type and quantity of binder can be used. Hence, materials which are cheaper than and as effective as cement should be selected. In this study, LGMgO, steel slag, hlime and PFA have been selected for cement replacement. The selection of binders was based on the effectiveness and cost of the materials compared to cement.

\section{Materials and Methods}

The materials and methods used in this research study are summarised in the following sections.

\subsection{Materials}

CEM1 [5] was used in this study. The chemical compositions of all materials used in the study are given in Table 1. LGMgO is a by-product of the calcination process of magnesite in a kiln at a temperature of $1100^{\circ} \mathrm{C}$. It is produced and sold by a Spanish company called Magnesitas Navarras, S.A. LGMgO was used as a cement substitute in this study. It is necessary to mention that $\mathrm{MgO}$ can be classified as low grade only if the $\mathrm{MgO}$ content is no more than 65 to $70 \%$. Pure (high grade) $\mathrm{MgO}$ contains up to 94 to $98 \%$ of dry weight $\mathrm{MgO}$ and the exposure limit is $10 \mathrm{mg} / \mathrm{m}^{3}$. The $\mathrm{MgO}$ obtained shows a narrow range of reactivity and is titled 'hard-burned'. PFA - F types [6] has been widely used for the stabilisation of hazardous wastes [7]. It is commonly used in S/S technology as a replacement material for cement and is commonly known as 'fly ash' in many countries. It is a by-product of coalfired power generation and has been used mainly to reduce the cost of solidification. In this study, PFA was selected as an alternative binder in order to demonstrate that the results are consistent with the literature and that the technique can be applied as a generic solution for waste treatment, regardless of the variation in the waste produced. The addition of hlime may help increase the $\mathrm{Ca}^{2+}$ and $\mathrm{OH}^{-}$ion concentration, which produces a better and faster hydration of PC. The use of lime-pozzolan binders can be quite helpful in reducing the product cost by using less cement. The ecologic profile of the material is improved with equivalent strength and durability performance with the usage of alternative lime-pozzolan materials instead of cement. Lime has some clear benefit on the quality of the mix. It has very fine particles which, during mixing, can occupy the empty spaces which cement particles cannot. Thus, it helps decrease or limits the flow of water and increases water retention in the fresh mix [1]. There are many different types of lime (e.g., hlime $\mathrm{Ca}(\mathrm{OH})_{2}$ and quicklime $(\mathrm{CaO})$ ) being produced worldwide. Hlime produced from limestone by calcination and hydration of the quicklime has been used in this study. The hlime [9] was used in this study and is mainly composed of $\mathrm{Ca}(\mathrm{OH})_{2}$ and $\mathrm{CaCO}_{3}$.

Table 1. Chemical Analysis of PC, LGMgO, PFA and HLIME

\begin{tabular}{c|c|c|c|c}
\hline & PC & LGMgO & PFA & HLIME \\
\hline Compound & $(\%)$ & $(\%)$ & $(\%)$ & $(\%)$ \\
\hline $\mathrm{CaO}$ & 63.78 & 10.53 & 1 & 10.2 \\
$\mathrm{SiO}_{2}$ & 20.33 & 7.50 & 45 & - \\
$\mathrm{Al}_{2} \mathrm{O}_{3}$ & 4.47 & 1.20 & 27 & 0.05 \\
$\mathrm{SO}_{3}$ & 3.09 & 76.40 & 1 & 3.2 \\
$\mathrm{Fe}_{2} \mathrm{O}_{3}$ & 2.52 & - & 0.3 & - \\
$\mathrm{MgO}$ & 1.07 & 3.12 & 7 & 0.2 \\
$\mathrm{~K}_{2} \mathrm{O}+\mathrm{Na}_{2} \mathrm{O}$ & 0.81 & - & - & 57.6 \\
\hline
\end{tabular}

\subsection{Methods}

\subsubsection{Physical and Chemical Characteristics of Solidified Samples}

Setting time, UCS before and after WI, ANC, workability, bulk density (BD) and moisture content (MC) measurements were conducted to analyse both the physical and chemical characteristics of the samples studied. The hazardous nature of the samples was determined after a curing period of 28 days followed by 64 days' testing according to the EA NEN7375:2004 [11]. The leaching characteristics of the products prepared were also tested using the ANC and granular leaching tests. The hazardous nature and leaching tests of the samples prepared are required since some waste/by-products of other production processes are used as a replacement material. The substitution ratios used in the research are depicted in Table 2 with the various w/s ratios given in Table 3. 
Table 2. Cement-binder substitution ratios - Screening Tests

\begin{tabular}{c|c|c}
\hline Mix & $\begin{array}{c}\text { CEMI } \\
(\%)\end{array}$ & Binder (\%) \\
\hline CEMI-BINDER-1:1 & 50 & 50 \\
CEMI-BINDER-1:2 & 33 & 67 \\
CEMI-BINDER-1:3 & 25 & 75 \\
CEMI-BINDER-1:4 & 20 & 80 \\
CEMI-BINDER-1:5 & 17 & 83 \\
CEMI-BINDER-1:6 & 14 & 86 \\
CEMI-BINDER-1:7 & 12.5 & 87.5 \\
CEMI-BINDER-1:8 & 11 & 89 \\
CEMI-BINDER-1:9 & 10 & 90 \\
\hline \multicolumn{2}{|c}{ Binder = Slag / LGMgO/ PFA / hlime }
\end{tabular}

Table 3. Water/solid (w/s) ratios (\%)

\begin{tabular}{|c|c|c|c|c|c|c|c|c|c|}
\hline CEMI-hlime & $\mathbf{1 : 1}$ & $\mathbf{1 : 2}$ & $\mathbf{1 : 3}$ & $\mathbf{1 : 4}$ & $\mathbf{1 : 5}$ & $\mathbf{1 : 6}$ & $\mathbf{1 : 7}$ & $\mathbf{1 : 8}$ & $\mathbf{1 : 9}$ \\
\hline Water (\%) & 60 & 60 & 60 & 60 & 60 & 60 & 60 & 60 & 60 \\
\hline CEMI-LGMgO & $\mathbf{1 : 1}$ & $\mathbf{1 : 2}$ & $\mathbf{1 : 3}$ & $\mathbf{1 : 4}$ & $\mathbf{1 : 5}$ & $\mathbf{1 : 6}$ & $\mathbf{1 : 7}$ & $\mathbf{1 : 8}$ & $\mathbf{1 : 9}$ \\
\hline Water (\%) & 40 & 40 & 45 & 45 & 50 & 50 & 50 & 50 & 50 \\
\hline CEMI-PFA & $\mathbf{1 : 1}$ & $\mathbf{1 : 2}$ & $\mathbf{1 : 3}$ & $\mathbf{1 : 4}$ & $\mathbf{1 : 5}$ & $\mathbf{1 : 6}$ & $\mathbf{1 : 7}$ & $\mathbf{1 : 8}$ & $\mathbf{1 : 9}$ \\
\hline Water (\%) & 20 & 20 & 20 & 20 & 20 & 20 & 20 & 20 & 20 \\
\hline CEMI-SLAG & $\mathbf{1 : 1}$ & $\mathbf{1 : 2}$ & $\mathbf{1 : 3}$ & $\mathbf{1 : 4}$ & $\mathbf{1 : 5}$ & $\mathbf{1 : 6}$ & $\mathbf{1 : 7}$ & $\mathbf{1 : 8}$ & $\mathbf{1 : 9}$ \\
\hline Water (\%) & 18 & 15 & 15 & 15 & 18 & 15 & 15 & 15 & 15 \\
\hline
\end{tabular}

The w/s ratios used in the grout varied depending on the workability of the product as the fineness of the material had a significant effect. Hlime is a fine, non-hydraulic material and does not set when in contact with water. On the other hand, slags do exhibit cementitious properties. PFA is a pozzolanic and hydraulic material which reacts when in contact with water. However, it requires less water compared to hlime due to its high MC and higher particle size distribution. The water demand of PFA is higher than for hlime, slag and $\mathrm{LGMgO}$ as received.

CEMI-PFA w/s ratios were varied between 18 and $25 \%$ with no significant variations in the results obtained. Consequently, $20 \%$ was selected as the optimal w/s ratio for these particular combinations. CEMI-slag combinations exhibited the same behaviour as PFA-blended grouts with water/solid ratio trials ranging between 15 and 20\%. A 15\% ratio was selected as it presented good workability results as well. The w/s ratio was increased to $18 \%$ only at a 1:1 mix ratio. CEMI-LGMgO needed more water $(\geq$ $40 \%$ ) for good workability results to be achieved. For ratios in excess of 1:5, the w/s ratio was kept constant at 50\%. The w/s ratios obtained and the mix designs tested were compared to results published in the literature. However, no comparison could be made in the case of $\mathrm{LGMgO}$ and steel slag as information is lacking on their use for the environmental applications (such as the treatment of hazardous waste using S/S technology). The results achieved in this study are similar to those obtained by other researchers as illustrated in Table 4.

Table 4. Mix Designs in the Literature

\begin{tabular}{|c|c|c|}
\hline Reference & Binding Systems (\% solids) & W/S ratio \\
\hline \multirow{2}{*}[10]{} & $40-100 \% \mathrm{AABFS}^{*}$ & $0.43-0.75$ \\
\hline & $40-100 \%$ CEMI & $0.28-0.63$ \\
\hline \multirow{2}{*}{ [11] } & $0-20 \%$ CEMI & \multirow{2}{*}{$0.29-0.45$} \\
\hline & 0-20\% CEM III Portland-slag & \\
\hline [12] & $75-100 \%$ CEMI & $0.265-0.310$ \\
\hline [13] & $10-100 \%$ CEMI & 0.17 \\
\hline [14] & $0-30 \%$ FA or CFA & 0.30 \\
\hline
\end{tabular}

$\mathrm{W} / \mathrm{S}=$ water/solid ratio; $* \mathrm{AABFS}=$ alkali activated blast furnace slag;

CEMI/CEMII/CEMIII=Ordinary Portland cement type I/type II/type III 


\section{Results And Discussions}

\subsection{Physical Characteristics of Solidified Products}

\subsubsection{UCS before and after Water Immersion}

Samples at various CEMI/binder ratios were prepared in triplicates, cured for 7, 28 (before and after WI) and 56 days and then tested. The results are depicted in Figs. 1-5, respectively. In addition to 28 days testing of strength, some samples were cured either for a shorter or longer period of time in order to verify the effect of the curing period on strength development. Certain selected samples were cured for 70, 120, 180, 365, 450 and 630 days and the results achieved are provided in Tables 5-8, respectively. With CEMI-only mix combinations, the w/s ratio was kept at 0.40 at all ages and the UCS results are shown in Fig. 1.

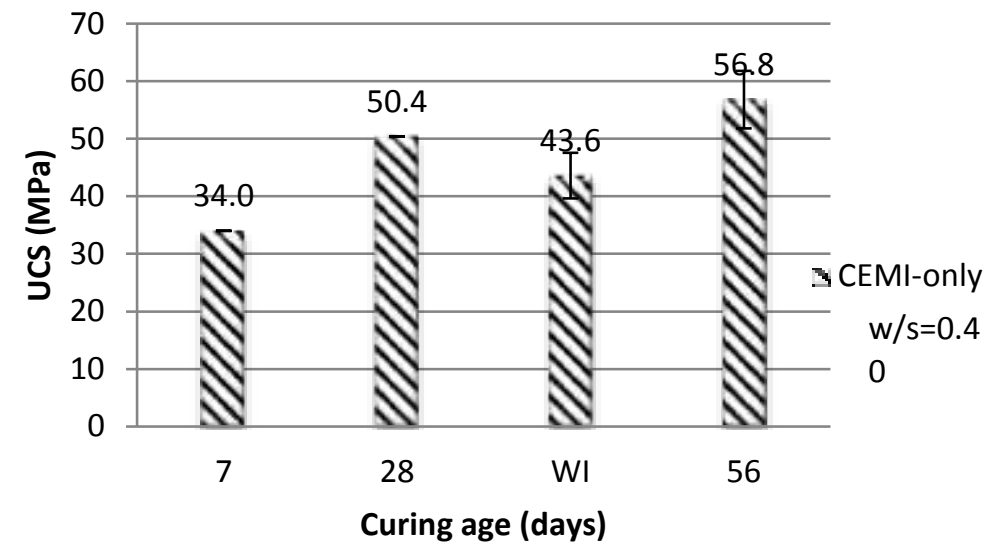

Figure 1. CEMI-only mix combinations for UCS 7, 28, 56 days and WI (28 days) *Error bars with standard deviations included

As illustrated in Fig. 1, strength development continued as the curing age increased from 7 to 56 days. Hence, longer curing age means better strength development in the case of cement-based mixtures. UCS increased by approximately $20 \%$ between 7 and 56 days while a $10 \%$ reduction was observed at 28 days curing age after WI. [15] suggested the measurement of UCS after immersion to check whether strength development is due to hydration rather than drying and if there is any matrix disruption. The matrix disruption is caused by matrix dissolution or deleterious swelling as a result of reactions with water (such as retardation of ettringite formation or hydration of silica gel). The results of this study would verify the fact that lower strength development at 28 days after WI may be due to the retardation of ettringite development. The drying of the specimens cannot possibly be the case under these circumstances since the samples are kept in a humidity room with a damp cloth in sealed plastic bags. Hlime was introduced into the grout in the range of 50-90\% to test its efficiency on strength development and to observe its performance as a cement substitute. In the literature, hlime has been widely used in the treatment of waste as in cement-blended mixtures. However, in previous studies, the ratio of cement was much higher than hlime, hence; cement was used as the dominant binder in the mixtures. In the present study, CEMI-hlime 1:1 to 1:9 ratios were tested instead of 2:1 to 9:1 ratios as widely tested by many other researchers [16], [17], [18], [19]. Therefore, a weak strength development was expected due to the lack of cementitious characteristics in hlime. The UCS results of CEMI-hlime mix ratios are depicted in the following Fig. 2.

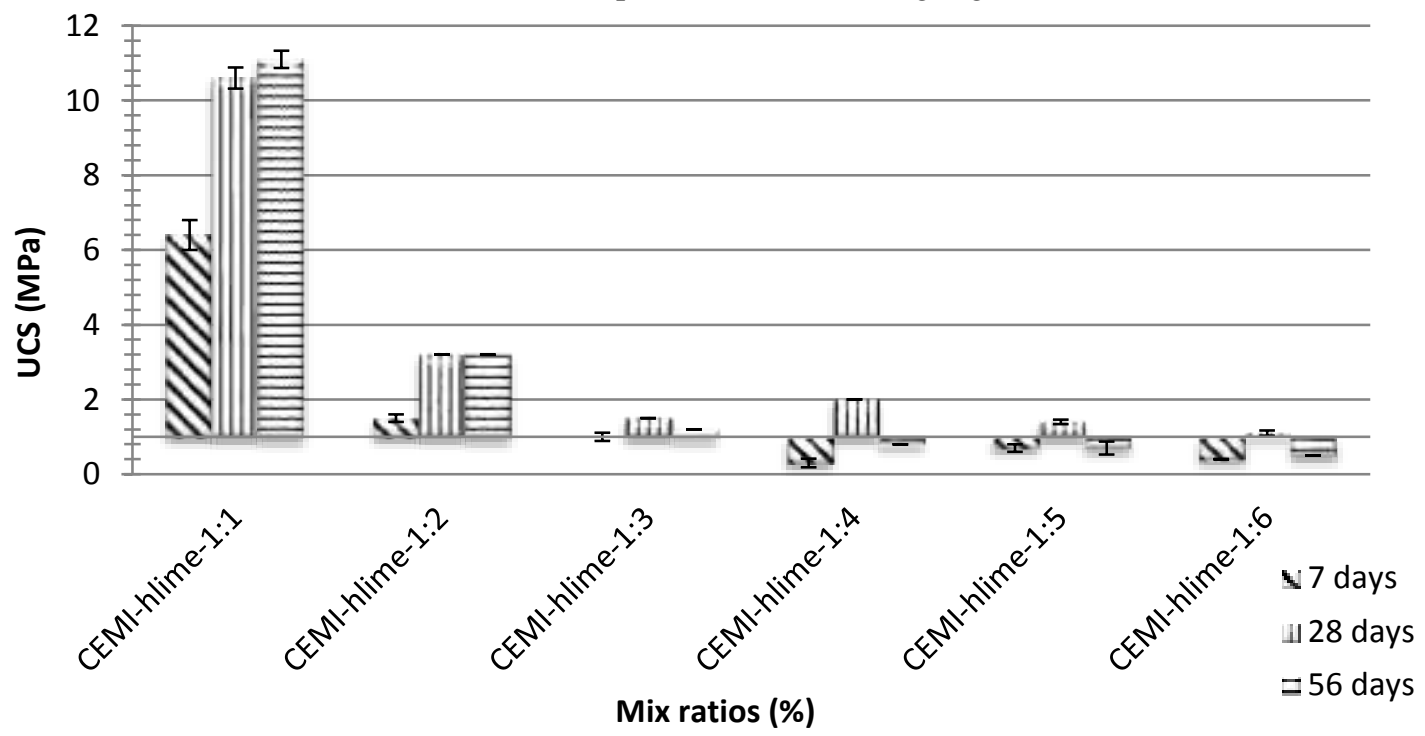

Figure 2. CEMI-hlime mix combinations for UCS 7, 28 and 56 days

*Error bars with standard deviations included 
According to the results illustrated in Fig. 2, UCS values of hlime-blended mixes are quite low when compared to the control sample, CEMI-only. UCS testing was only done for ratios of up to 1:6 as the UCS values were well below 1 MPa and the grout never developed a strength that could be measured after 7, 28 or 56 days at 1:7, 1:8 and 1:9 mix ratios. Strength development was reasonably high only at CEMI-hlime 1:1 and 1:2 ratios and the rest was not sufficient to be considered for further testing. When it comes to environmental application, It is a requirement of the WAC that only mixtures with sufficient strength development $\left(\mathrm{UCS}_{28 \mathrm{~d}}>1 \mathrm{MPa}\right)$ should be considered for further testing, including ANC, monolithic and granular leaching tests. The weak strength development observed could be linked to the high w/s ratio selected (0.60) and to the lower cement content compared to previous studies as mentioned earlier. The amount of cement is not sufficient for hydration reactions and hence strength development. The large amount of water requires more cement to be reacted in order for the hydration to be completed. In addition, hlime being a fine material, the particles does not allow the available cement particles to get in touch with water for an effective hydration reaction to take place. WI testing was only conducted for the first two ratios $(1: 1$ and $1: 2)$ and the results are shown in Table 5. According to these results, strength development after WI was slightly better than before. This was mainly valid in hlimeblended mix combinations as most of the other blends had lower strength development after WI as can be seen in the UCS results reviewed throughout the paper. This could be linked to the fact that rehydration occurred during WI where cement particles found a way to interact with water for hydration.

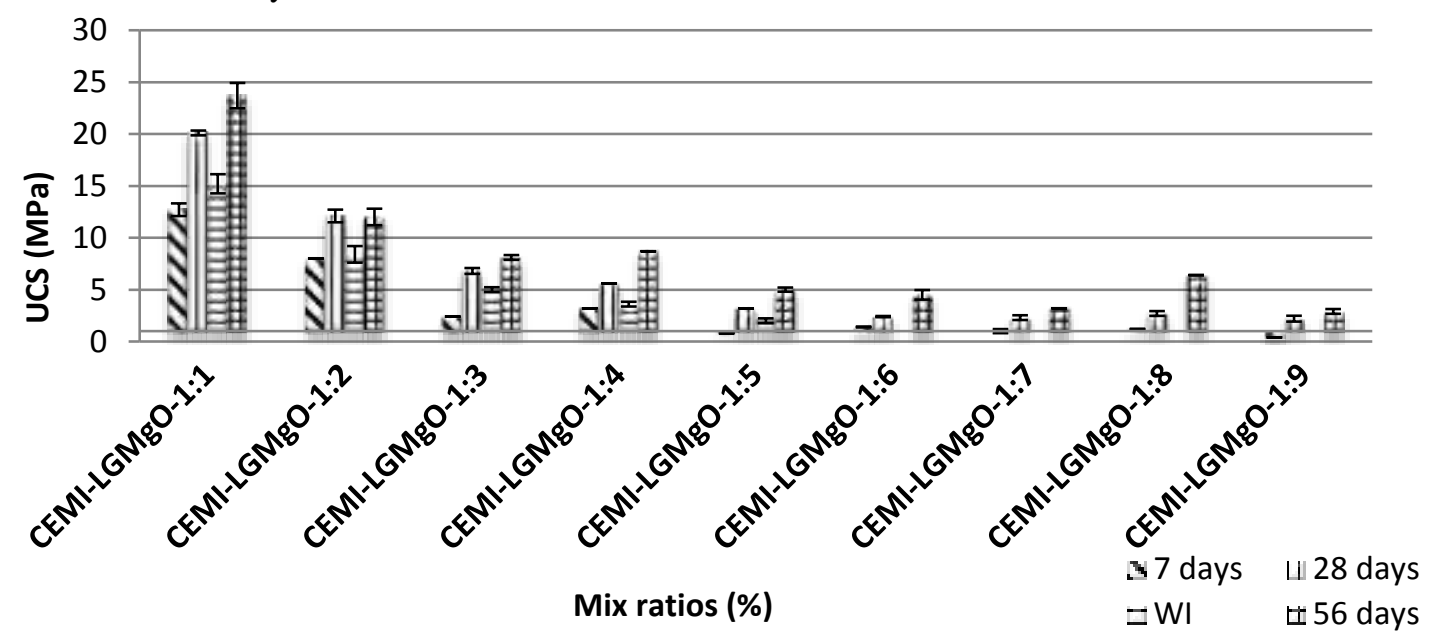

Figure 3. CEMI-LGMgO mix combinations for UCS 7, 28, and 56 days and WI (28 days)

*Error bars with standard deviations included

In Fig. 3, UCS results for CEMI-LGMgO mix combinations are shown. Similar behaviour was noticed as UCS results for CEMI-hlime mix combinations, where a longer curing period means better strength development. Moreover, UCS values decreased after WI. A problem in the matrix physical integrity might be suggested in these samples due to the reduction in strength after WI. The weaker strength development after WI could be linked to the delayed ettringite formation in the presence of excess water. This might cause matrix disruption as a result of expansion caused by ettringite formation. As it is clear from the results, strength development continued with longer curing ages, which confirms continuing hydration reactions taking place [15],[20]. Overall, all ratios achieved better strength development compared to hlime-blended mixtures whereas most of the ratios, regardless of curing age, achieved UCS values higher than $1 \mathrm{MPa}$. Various w/s ratios were used in those blends as higher LGMgO content required more water to achieve a good consistency. It is clear that LGMgO has similar hydration characteristics as cement, which is much better than hlime. Strength development continues at longer curing ages and LGMgO is reactive enough when in contact with water to produce hydration reactions and products that are required for strength development. PFA-blended mixes were also considered as PFA has been widely used in the environmental applications (i.e. in the treatment of hazardous waste) and in the substitution of cement due to its pozzolanic properties. The UCS results obtained with PFA additions are shown in Fig. 4.

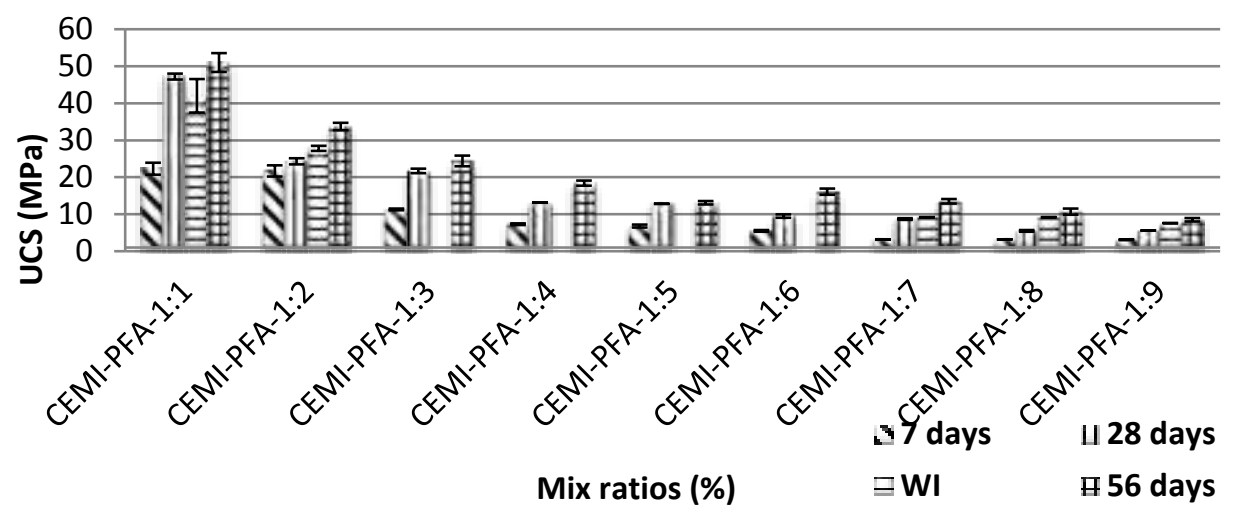

Figure 4. CEMI-PFA mix combinations for UCS 7, 28 and 56 days, WI (28 days) *Error bars with standard deviations included 
As seen in Fig. 4, all the mix designs studied have met the UCS WAC limit (>1 MPa). In environmental applications like waste stabilisation, waste could be incorporated in any ratio as strength development continued even after 56 days and the values were quite high, and thus may be affected less by waste incorporation when compared to other blends studied. Those with WI test results demonstrated better strength development compared to before WI. The cementitious properties of PFA are effective in activating the hydration reactions required for strength development. The retardation of ettringite was possibly reduced by the pozzolanic characteristics of PFA which formed cementitious materials required for the completion of hydration when in contact with water and cement. Overall, hlime and PFA results showed a development in strength after WI where CEMI-only, LGMgOblended and slag-blended mix combinations demonstrated a weak strength development after WI. However, all exhibited a similar trend of strength development with longer curing.

The slag-blended mixtures were tested according to its effect on strength development and the results achieved are depicted in Fig. 5. According to the results obtained, it is clear that slag achieves much better strength development than hlime, LGMgO and even PFA, with UCS values increasing up to $50 \mathrm{MPa}$. Moreover, all ratios tested yielded higher than $5 \mathrm{MPa}$, regardless of the curing age, well above the UCS WAC limit (1MPa). The blends showed promising strength development even at 7 days of curing and it continued even after 56 days. There were only slight differences in the results obtained before and after WI.

Some further extended tests were conducted on several selected mix designs to show the effect of curing age on strength development. Tables 5-8 illustrate these extended testing results. CEMI-hlime mix designs showed a consistent behaviour and only CEMI-hlime with a 1:1 ratio had a good UCS value at 630 days. CEMI-LGMgO combinations showed continued strength development with increased curing age. A similar behaviour was observed for most of the CEMI-PFA and CEMI-slag mix combinations.

The w/s ratios used in the experiments are also shown in Table 5-8. PFA does not require as much water as hlime does. This is due to the water content in the as received PFA. The water required for hydration is provided both by the addition of extra water into the mix blends and by the water content of PFA itself. On the other hand, slag does not contain as much water as PFA and the w/s ratio used in the mix blends are low. The lower w/s ratios used in the slag-blended mixtures resulted in better strength development.

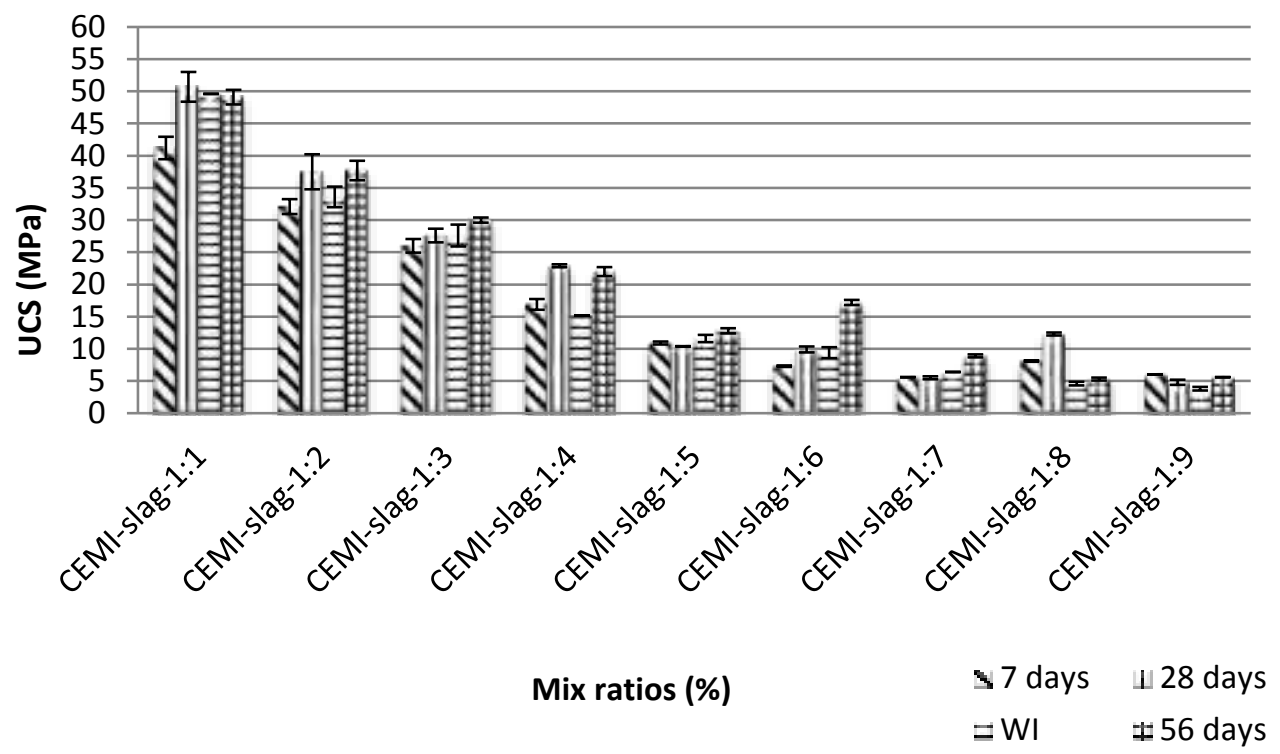

Figure 5. CEMI-slag mix combinations for UCS 7, 28, and 56 days, WI (28 days)

*Error bars with standard deviations included

\subsubsection{Bulk Density Results}

Fig. 6 shows BD results for CEMI-only mix combinations at different curing ages. BD values remained almost constant for CEMI-only mix combinations with increasing curing age. A constant w/s ratio of 0.40 was used for all curing ages. 


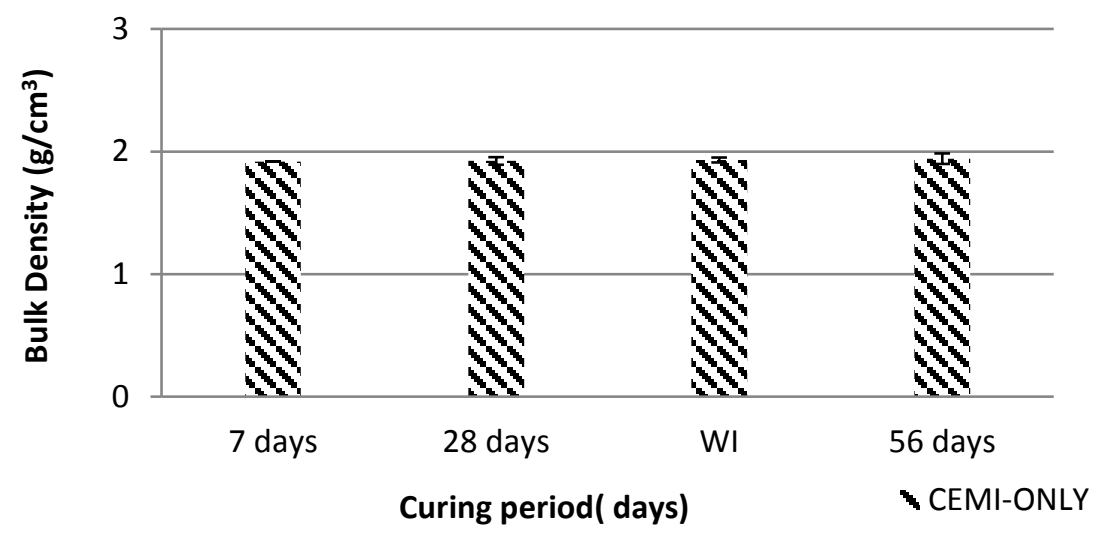

Figure 6. CEMI-only - BD $\left(\mathrm{g} / \mathrm{cm}^{3}\right)$

*Error bars with standard deviations included

BD results for CEMI-hlime and CEMI-LGMgO mix combinations are depicted in Figs. 7 and 8, respectively. A similar approach was used for the CEMI-hlime mix combinations where a constant w/s ratio (0.60) was used at all ratios studied. The w/s ratio only changed for CEMI-hlime 1:2 ratios to 0.65 where a change in the BD values was observed. The w/s ratio was kept constant at 0.60 for all other ratios studied and no significant difference was observed. Therefore, it was concluded that the incorporation of hlime into the mix matrix and a longer curing age had no significant effect on BD. The w/s ratio, on the other hand, did have an impact on BD values. All the ratios studied had BD values ranging from 1.50 to $1.6 \mathrm{~g} / \mathrm{cm}^{3}$. CEMI-only mix combinations had higher BD values than CEMI-hlime mix combinations. Therefore, it may be concluded that higher BD values mean higher UCS values.

For CEMI-LGMgO combinations, the w/s ratio was increased with increasing the LGMgO content in the mixture. Therefore, it is difficult to critically analyse the effect of these two factors on BD results. The results, depicted in Fig. 8, clearly show that there is no clear trend in the BD values where a conclusion could be derived on what has caused the change in values. The only conclusion that may be reached is the fact that the BD values varied between $1.75-1.94 \mathrm{~g} / \mathrm{cm}^{3}$ regardless of the curing age and LGMgO content in the mixture. The results achieved were not significantly different and can be considered as negligible. No clear effect of $\mathrm{w} / \mathrm{s}$ ratio, curing ages and $\mathrm{LGMgO}$ content was observed on the $\mathrm{BD}$ values.

The BD results for CEMI-PFA and CEMI-slag mix combinations are shown in Figs. 9 and 10, respectively. Apparent increases in BD values for slag blends were observed at all ratios studied compared to hlime, PFA, LGMgO and cement-only mix combinations. Slag-blended mixtures had values higher than $2 \mathrm{~g} / \mathrm{cm}^{3}$, which was the highest BD value achieved among all the mix combinations tested. Steel slag is a heavy material compared to other binding agents used in the study. Hence, achieving higher BD values was expected.

Table 5 CEMI-hlime mix combinations for UCS WI, 180 and 630 days

\begin{tabular}{c|c|c|c|c}
\hline \multirow{2}{*}{ Mix } & \multicolumn{4}{c}{$\begin{array}{c}\text { Curing period (days) } \\
\text { UCS values (MPa) }\end{array}$} \\
\cline { 2 - 5 } & WI & $\mathbf{1 8 0}$ d & $\mathbf{6 3 0}$ d & w/s ratio \\
\hline CEMI-hlime 1:1 & 10.9 & NA & 11.8 & 0.6 \\
\hline CEMI-hlime-1:2 & 3.4 & NA & NA & 0.6 \\
\hline CEMI-hlime-1:3 & NA & 1.6 & NA & 0.6 \\
CEMI-hlime-1:4 & NA & 0.4 & 0.4 & 0.6 \\
\hline $\begin{array}{l}\text { CEMI-hlime-1:5 } \\
\text { CEMI-hlime-1:6 }\end{array}$ & NA & 0.1 & 0.3 & 0.6 \\
\hline
\end{tabular}


Table 6 CEMI-LGMgO mix combinations for UCS 70 and 180 days

\begin{tabular}{c|c|c|c}
\hline \multirow{2}{*}{ Mix } & \multicolumn{3}{c}{$\begin{array}{c}\text { Curing period (days) } \\
\text { UCS values (MPa) }\end{array}$} \\
\cline { 2 - 4 } & $\mathbf{7 0 ~ d}$ & $\mathbf{1 8 0}$ d & w/s ratio \\
\hline CEMI-LGMgO-1:1 & 22.4 & NA & 0.40 \\
\hline CEMI-LGMgO-1:2 & 16.8 & NA & 0.40 \\
\hline CEMI-LGMgO-1:3 & 10.1 & NA & 0.45 \\
\hline CEMI-LGMgO-1:4 & 3.9 & NA & 0.45 \\
\hline CEMI-LGMgO-1:5 & 2.4 & NA & 0.50 \\
\hline CEMI-LGMgO-1:6 & 2.4 & 3.0 & 0.50 \\
\hline CEMI-LGMgO-1:7 & NA & 3.8 & 0.50 \\
\hline CEMI-LGMgO-1:8 & 3.6 & 3.6 & 0.50 \\
\hline CEMI-LGMgO-1:9 & 3.6 & 3.0 & 0.50 \\
\hline
\end{tabular}

Table 7 CEMI-PFA mix combinations for UCS 90 days and WI

\begin{tabular}{c|c|c|c}
\hline \multirow{2}{*}{ Mix } & \multicolumn{3}{c}{$\begin{array}{c}\text { Curing period (days) } \\
\text { UCS values (MPa) }\end{array}$} \\
\cline { 2 - 4 } & WI & 90 d & w/s ratio \\
\hline CEMI-PFA-1:1 & 42.0 & 36.4 & 0.20 \\
\hline CEMI-PFA-1:2 & 27.8 & NA & 0.20 \\
\hline CEMI-PFA-1:3 & NA & NA & 0.20 \\
\hline CEMI-PFA-1:4 & NA & NA & 0.20 \\
\hline CEMI-PFA-1:5 & NA & NA & 0.20 \\
\hline CEMI-PFA-1:6 & NA & NA & 0.20 \\
\hline CEMI-PFA-1:7 & 9.2 & 12.3 & 0.20 \\
\hline CEMI-PFA-1:8 & 9.2 & 11.6 & 0.20 \\
\hline CEMI-PFA-1:9 & 7.6 & NA & 0.20 \\
\hline
\end{tabular}

Table 8 CEMI-slag mix combinations for UCS 70 and 120 days

\begin{tabular}{l|c|c|c}
\hline \multirow{2}{*}{ Mix } & \multicolumn{3}{c}{$\begin{array}{c}\text { Curing period (days) } \\
\text { UCS values (MPa) }\end{array}$} \\
\cline { 2 - 4 } & $\mathbf{7 0 ~ d}$ & $\mathbf{1 2 0 d}$ & w/s ratio \\
\hline CEMI-slag-1:1 & NA & NA & 0.18 \\
\hline CEMI-slag-1:2 & 46.4 & NA & 0.15 \\
\hline CEMI-slag-1:3 & NA & NA & 0.15 \\
\hline CEMI-slag-1:4 & 32.5 & NA & 0.15 \\
\hline CEMI-slag-1:5 & 20.4 & 13.6 & 0.15 \\
\hline CEMI-slag-1:6 & 22.0 & NA & 0.15 \\
\hline CEMI-slag-1:7 & NA & 8.4 & 0.15 \\
\hline CEMI-slag-1:8 & NA & NA & 0.15 \\
\hline CEMI-slag-1:9 & NA & NA & 0.15 \\
\hline
\end{tabular}

In summary, the following conclusion can be derived on BD values for the various blends studied: $\mathrm{BD}_{\mathrm{hlime}}<\mathrm{BD}_{\mathrm{PFA}}<\mathrm{BD} \mathrm{LGMgO}_{\mathrm{L}}$ $<\mathrm{BD}_{\text {CEMI-only }}<\mathrm{BD}_{\text {SLAG. }}$ This shows that although BD is an important indicator and influences the UCS, the strength level achieved is mostly affected by the amount of cementitious materials available for hydration reactions. 


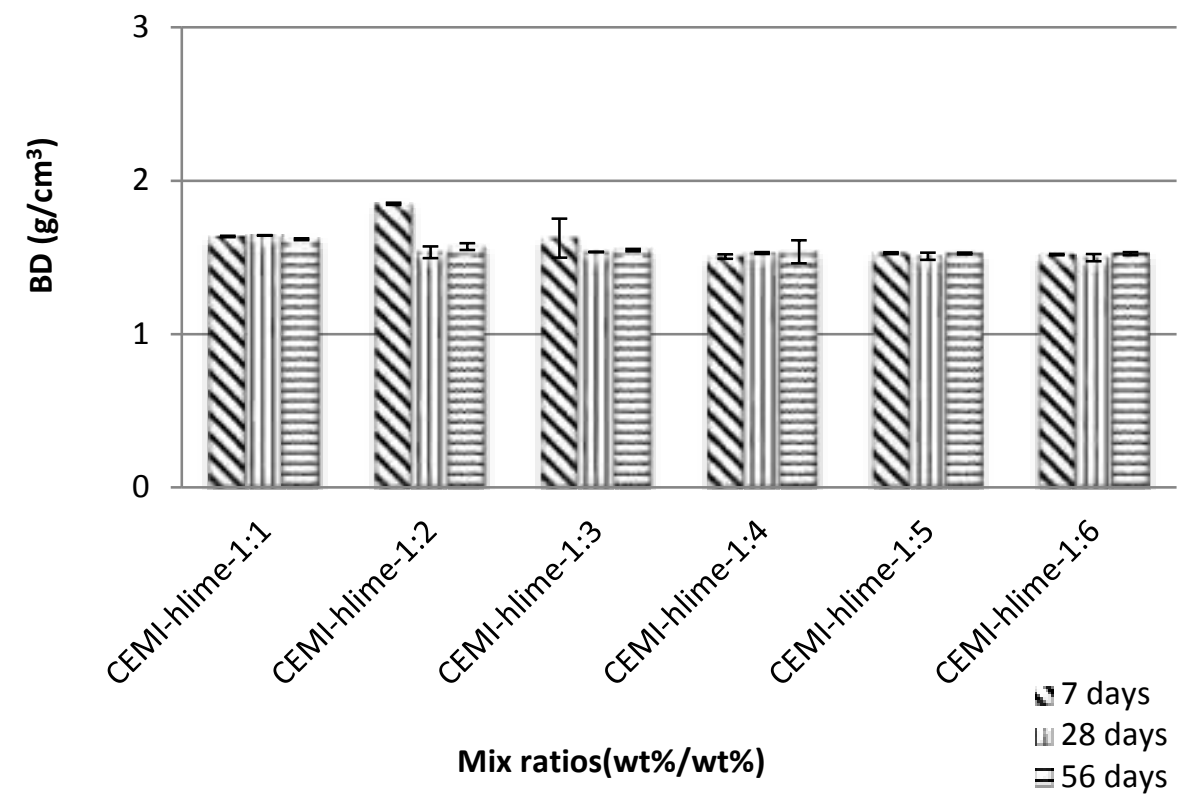

Figure 7 CEMI-hlime - BD $\left(\mathrm{g} / \mathrm{cm}^{3}\right)$

*Error bars with standard deviations included

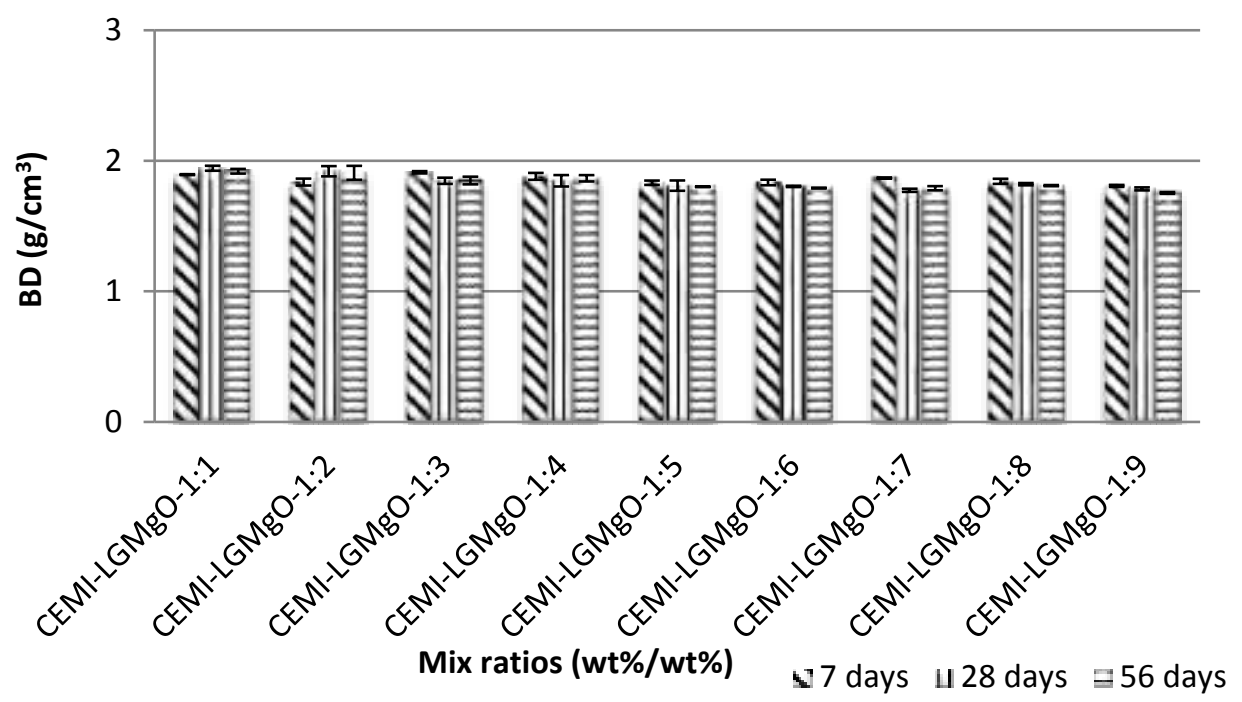

Figure 8. CEMI-LGMgO - BD $\left(\mathrm{g} / \mathrm{cm}^{3}\right)$

*Error bars with standard deviations included

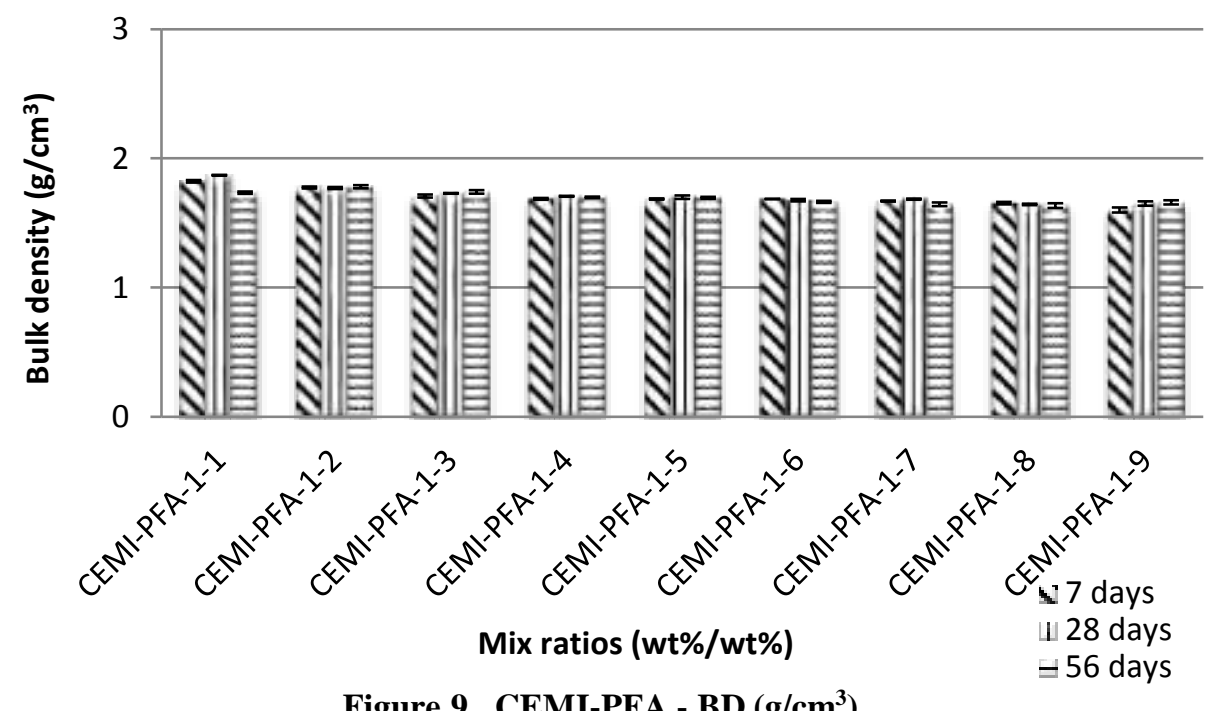

Figure 9. CEMI-PFA - BD (g/ $\left.\mathrm{cm}^{3}\right)$

* Error bars with standard deviations included 


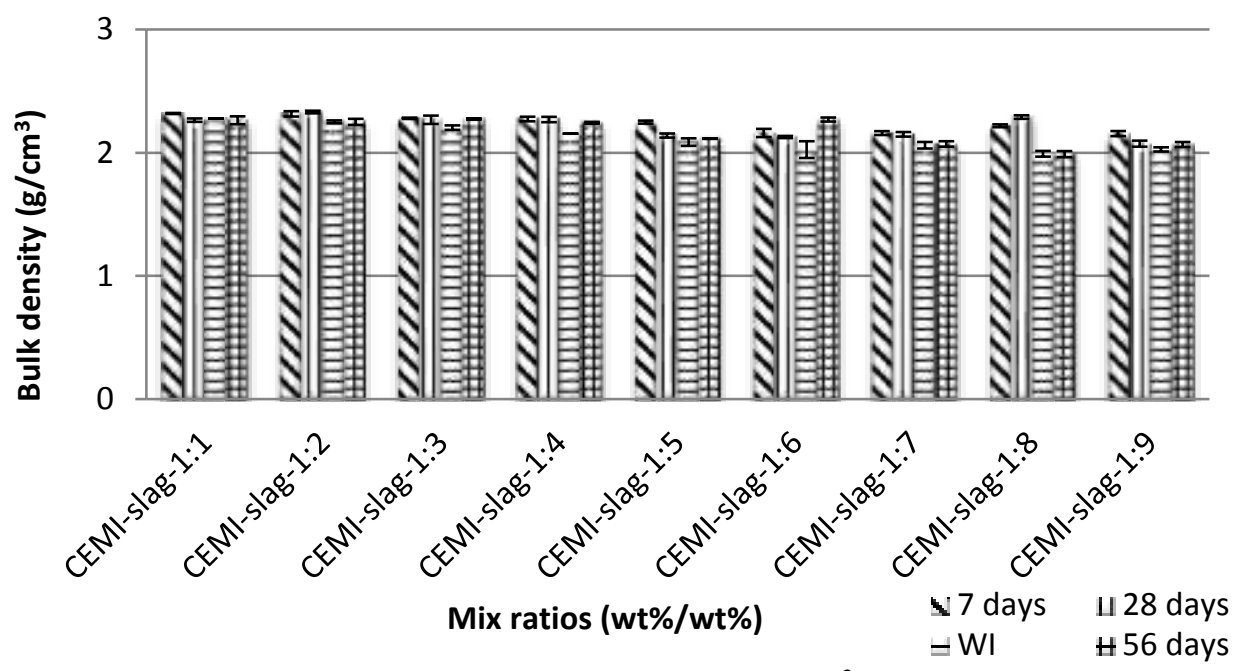

Figure 10. CEMI-slag - BD $\left(\mathrm{g} / \mathrm{cm}^{\mathbf{3}}\right)$

*Error bars with standard deviations included

\subsubsection{Moisture Content (MC)}

The water content (as a percentage) of samples studied is depicted in Figs. 11 to 15 for samples studied. The results show that hlime-blended mixtures achieved the highest water content values. This may be linked to the high w/s ratios used. When the strength values achieved are taken into account, it may be concluded that the water was not used effectively for the hydration reactions taking place and hence strength development was very weak. Thus, the un-hydrated cement particles remained in the blends along with an excessive amount of unused water. In the literature, lime is often added to sludge type mixes which already have a high water content in order to reduce the MC and to reach the desired level of compaction [21]. The decrease in the MC helps to enhance the workability of the grout. In contrast, when hlime was introduced into the mixture in this study, the amount of water was increased in order to achieve a reasonable workability which, as a consequence, decreased the strength development of the S/S product. The curing age has a clear effect on the MC of the samples. This is due to the continuing hydration reactions taking place in the mixture. All ratios studied achieved the lowest MC values at 56 days of curing age. The water content of the LGMgO-blended mix designs was not as high as for the hlime-based mix matrix. This may be linked to the smaller w/s ratio used in the matrix. PFA and slag-blended mixtures used approximately the same w/s ratio. However, PFA, as received, already contains some water. Hence, the lower water content means better hydration reactions and better strength development [20]. Slag-blended mixtures had quite low MC values compared to other mix blends. This may be linked to the low w/s ratio used in the mix design or to the good quality of hydration reactions that took place in the matrix. In the literature, work focusing on the use of another type of slag, GGBS, showed that water used in the matrix design increased with the increase of GGBS content [22]. In this study, the water content was reduced as it was used with increasing slag content and hence the available water was used effectively in the slag-blended mix matrix.

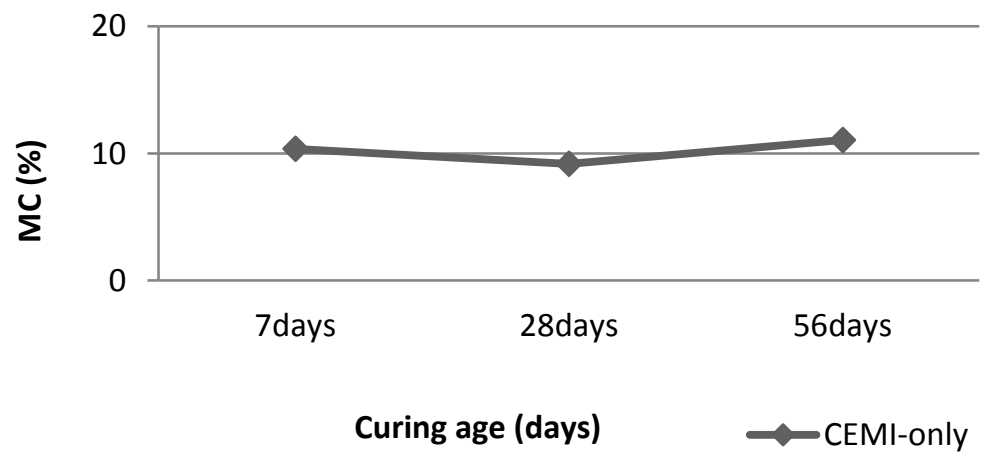

Figure 11. CEMI-only - MC (\%)

\subsubsection{Consistency}

The properties of the fresh grouts are evaluated by determining their workability and the results are depicted in Figs. 16 to 19 . The consistency of the grouts is reported as an average value for the samples prepared for 7, 28, 56 days and WI testing. The 
consistency and MC of the mixes were measured to control water addition. A sufficient amount of water was added to form a mortar-like mix. The water/cement ratio determines the effect of the water content since it introduces the concept of the workability required when the material is to be mixed, poured and cast [23]. MC is an important tool not just because it affects the water/binder ratio, but also has an effect on the workability, strength and permeability of the samples. As [24] pointed out in the case of PC, the water/binder ratio needs to be 0.23 . The further addition of any amount of water required for cement hydration will cause an increase in both porosity and permeability. As previously mentioned by [25], the addition of cement significantly reduces the MC of the samples. Since this study focuses on decreasing cement usage, the effect of other materials (hlime, LGMgO, PFA, steel slag) on the MC, consistency and BD are discussed. For CEMI-hlime mix combinations where a constant w/s ratio was used, the quality of the consistency decreased with the addition of more lime into the mix matrix. The values were in the range of 160 to $212 \mathrm{~mm}$. It is difficult to comment on CEMI-LGMgO consistency results as both the w/s and binder/cement ratios were changed. Hence, the results achieved do not follow a specific trend. However, at 1:1 and 1:2 ratios where w/s ratio was constant, a decrease in consistency was observed with an increase in LGMgO content. The consistency values were in the range of 186 to $225 \mathrm{~mm}$ with only 1:2 and 1:4 mixes exhibiting values within the WAC limits $(175 \pm 10 \mathrm{~mm})$.

The consistency results for CEMI-PFA mix blends are depicted in Fig. 18. According to this data, it is difficult to comment on PFA-blended mixtures' consistency results as no particular trend can be observed. The results achieved were in the range of 192 to $224 \mathrm{~mm}$, which is much higher than the WAC limits $(175 \pm 10 \mathrm{~mm})$. This may be linked to the excess amount of water added or simply to the water coming from the PFA itself. Fig. 19 summarises the consistency results for CEMI-slag mix blends. The values are in the range of 177 to 213 , higher than the WAC limits even at very low w/s ratios $(0.15-0.20)$. This is due to the fact that further hydration is retarded within a few minutes of exposure to water because of a coating of aluminosilicate forms on the surface of slag grains [26]. Under these conditions, the rate of hydration is very slow and can only be accelerated in alkaline media where the alkalinity can be provided by either lime or PC clinker [27].

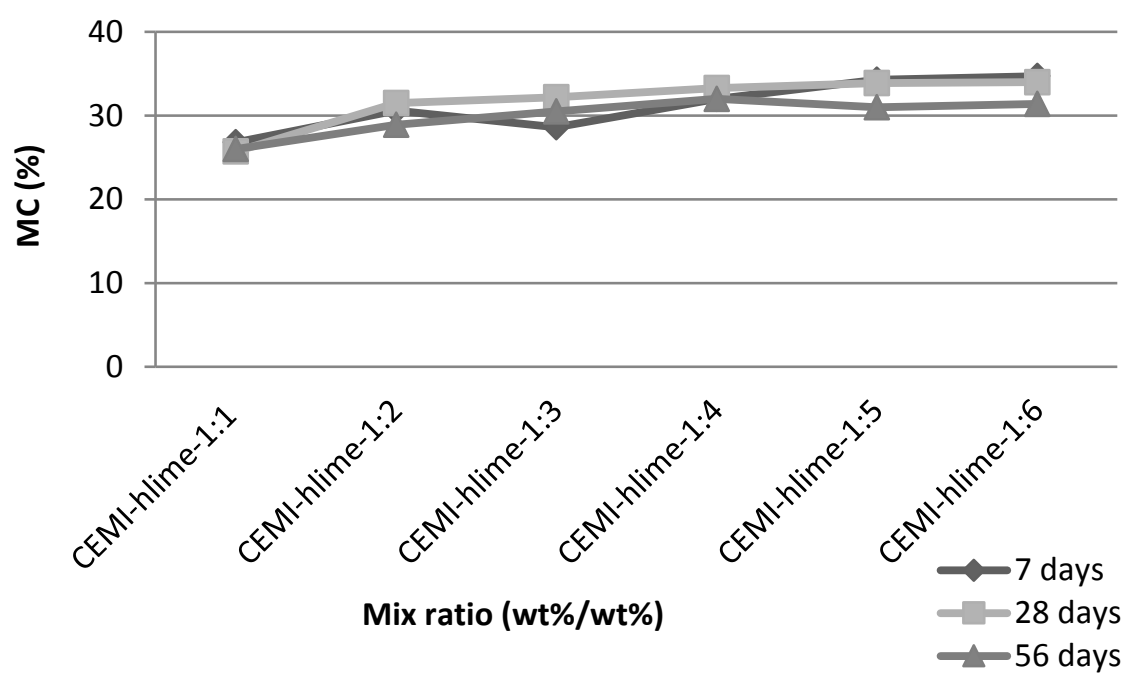

Figure 12. CEMI-hlime - MC (\%)

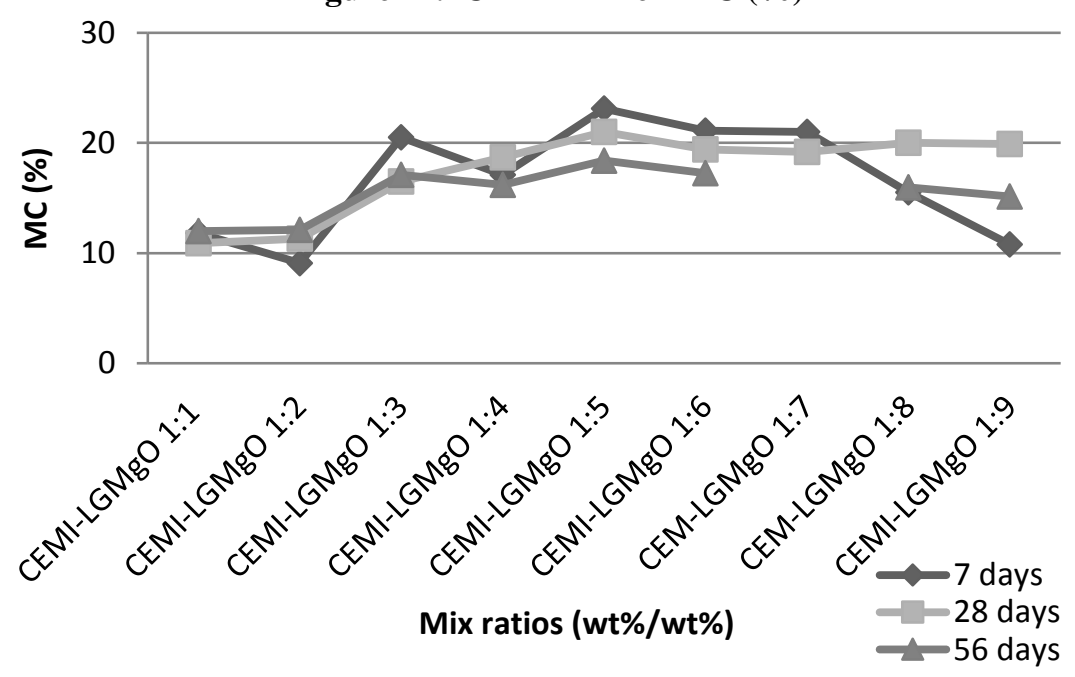

Figure 13. CEMI-LGMgO - MC (\%) 


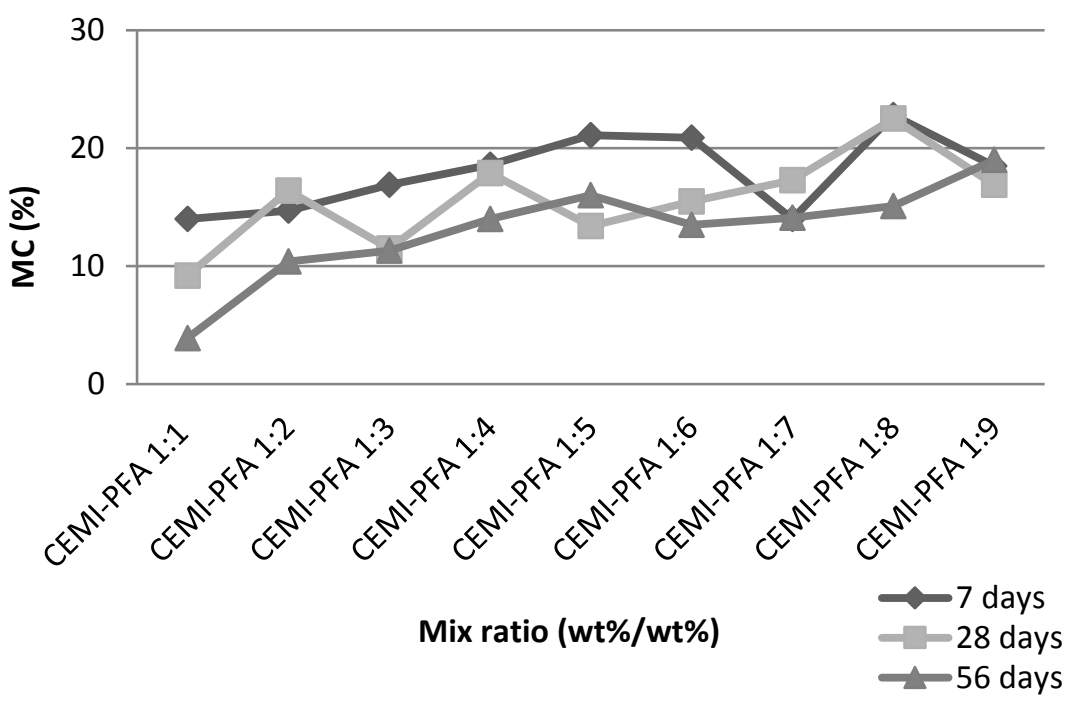

Figure 14. CEMI-PFA - MC (\%)

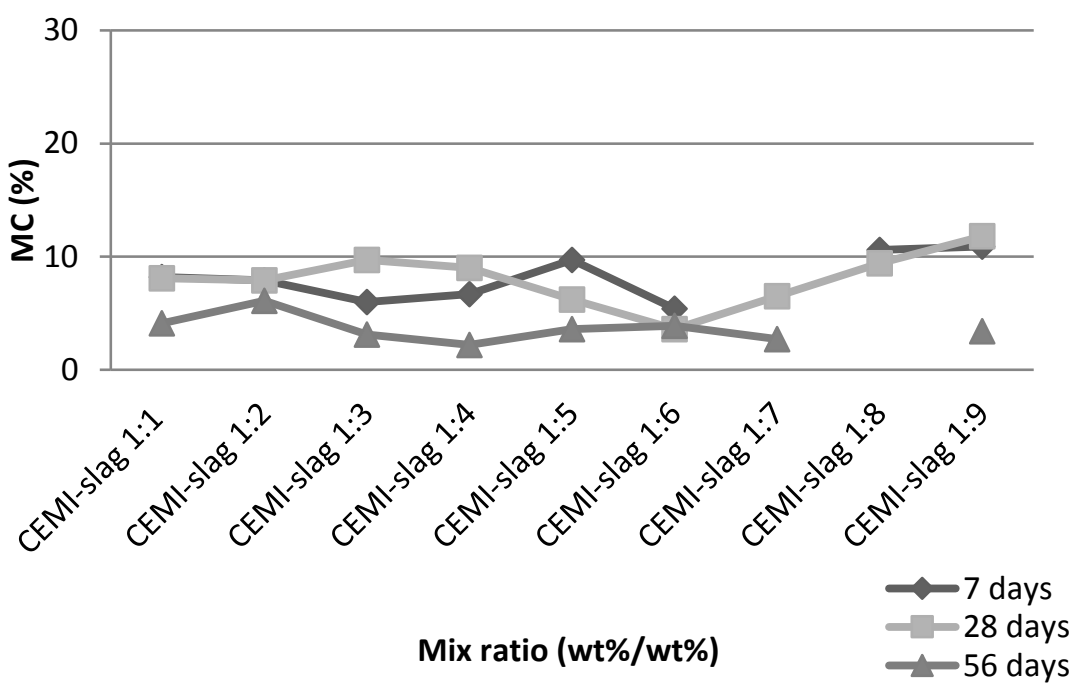

Figure 15. CEMI-slag - MC (\%)

\subsubsection{Specific gravity}

The specific gravity results of the materials as received are shown in Table 12 . The specific gravity values of the steel slag and LGMgO used in the study are quite similar with less than 5\% difference. On the other hand, hlime and PFA used in the study had similar values but significantly lower than CEMI and LGMgO values. When compared to water which has a specific gravity of 1 , all materials studied are denser than water and hence will sink in it. CEMI, slag and LGMgO are denser than hlime and PFA. Steel slag, CEMI and LGMgO are expected to yield a higher density products compared to conventional mixes having less specific gravity values.

\subsubsection{Setting Time}

Setting time, both initial and final, of the mortar were tested using a manual Vicat apparatus. The setting time was measured for all CEMI-lime and CEMI-LGMgO mix combinations but only for selected combinations of CEMI-PFA and CEMI-slagblended mix matrices. Setting time measurements were only undertaken for one sample during the first stage of the research. The initial and final setting time results are shown in Figs. 20 to 24. The results show that PFA and slag-blended mix designs set in a shorter period of time at all binder ratios studied when compared to LGMgO and hlime blends. On the other hand, hlime-blended mix designs had faster initial setting time results but slower final setting time when compared to LGMgO blends. LGMgO had much longer values for both initial and final setting compared to CEMI-only.

The chemical characterisation and elemental composition of materials used in the study provide information on what has affected the setting time. The pozzolanic characteristics of both steel slag and PFA result in quicker stiffening and hence more rapid setting than for hlime. In hlime-blended mixtures, the setting was slowed down due to the lack of pozzolanic behaviour of hlime that is required to set when in contact with water and hence the hydration process that is required for the stiffening and hardening of the matrix. According to the setting time results attained, LGMgO lacks pozzolanic properties compared to slag and PFA. LGMgO is a reactive material that reacts when in contact with water. However, the setting of LGMgO-blended mixtures took longer compared to CEMI-only mixes. 


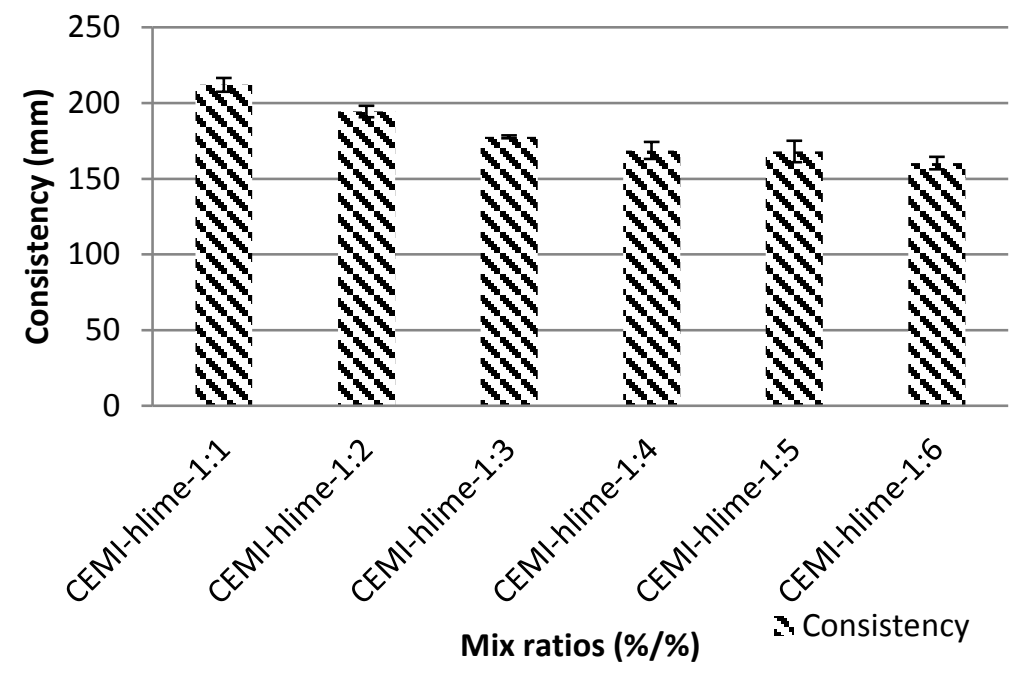

Figure 16 CEMI-hlime Consistency (mm)

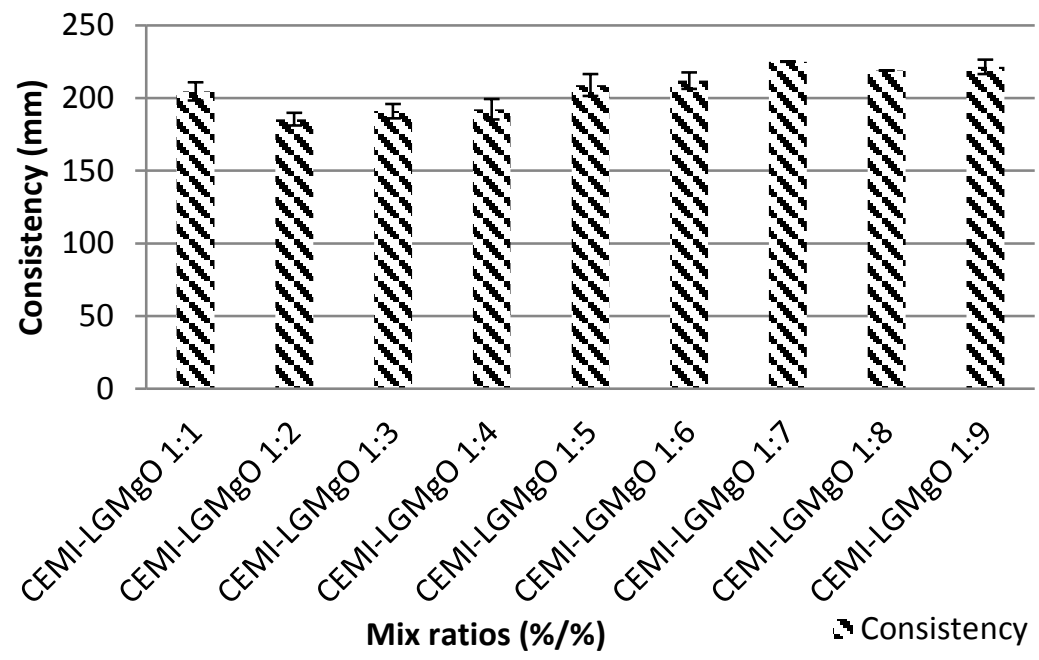

Figure 17 CEMI-LGMgO Consistency (mm)

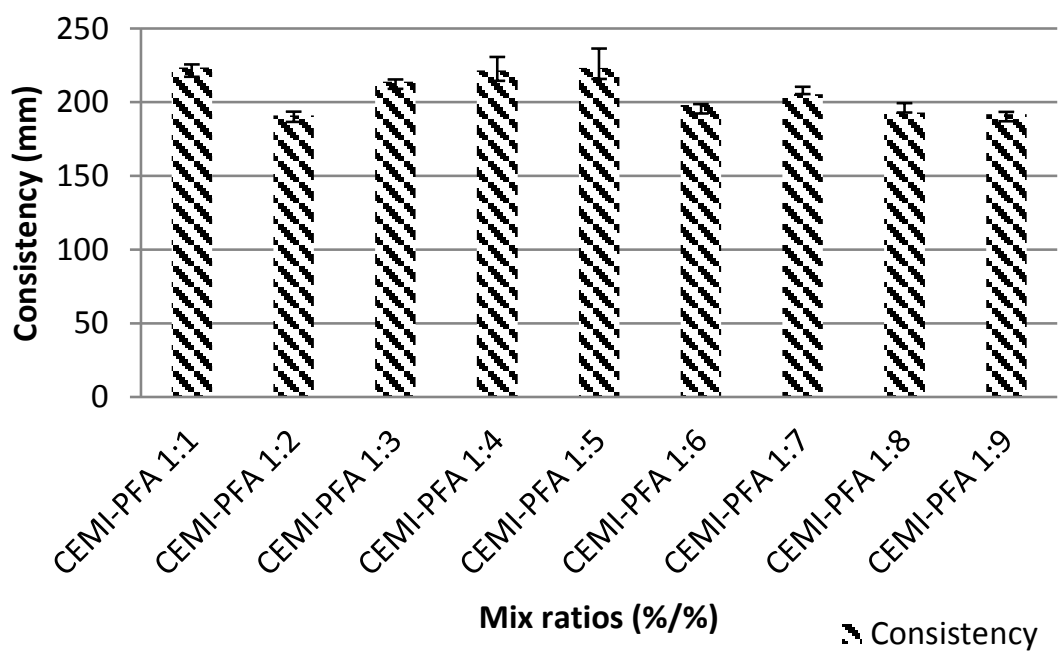

Figure 18 CEMI-PFA Consistency (mm) 


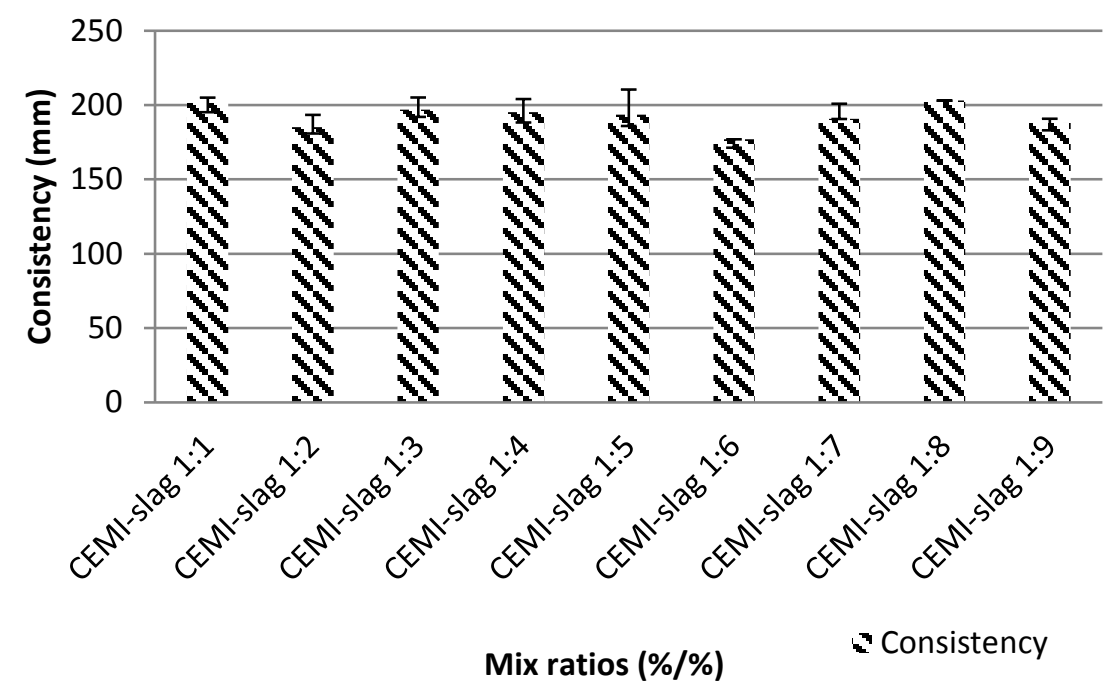

Figure 19 CEMI-slag Consistency (mm)

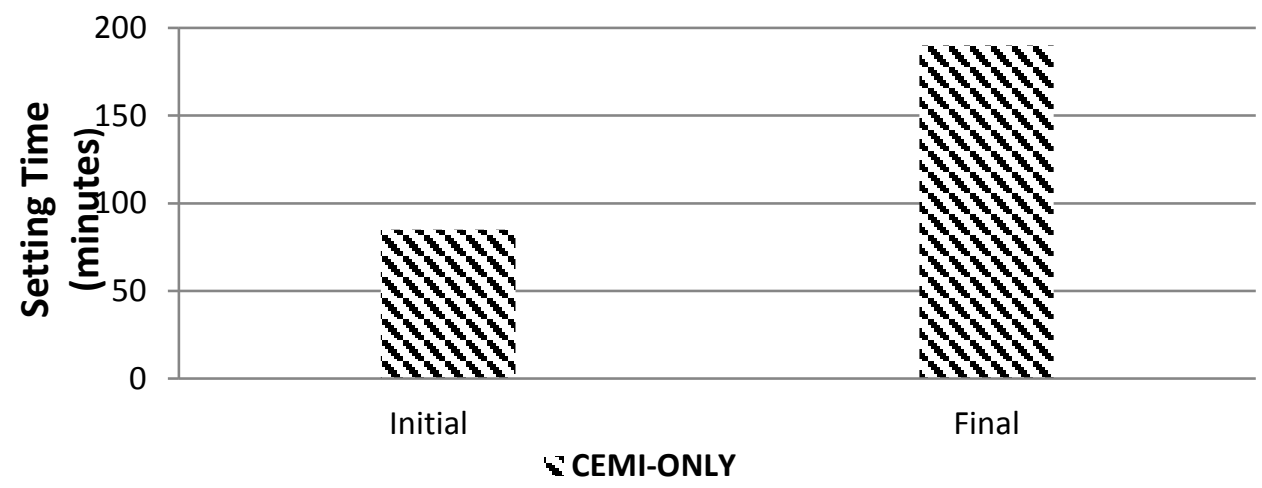

Figure 20 CEMI-only

The effect of cement on setting time

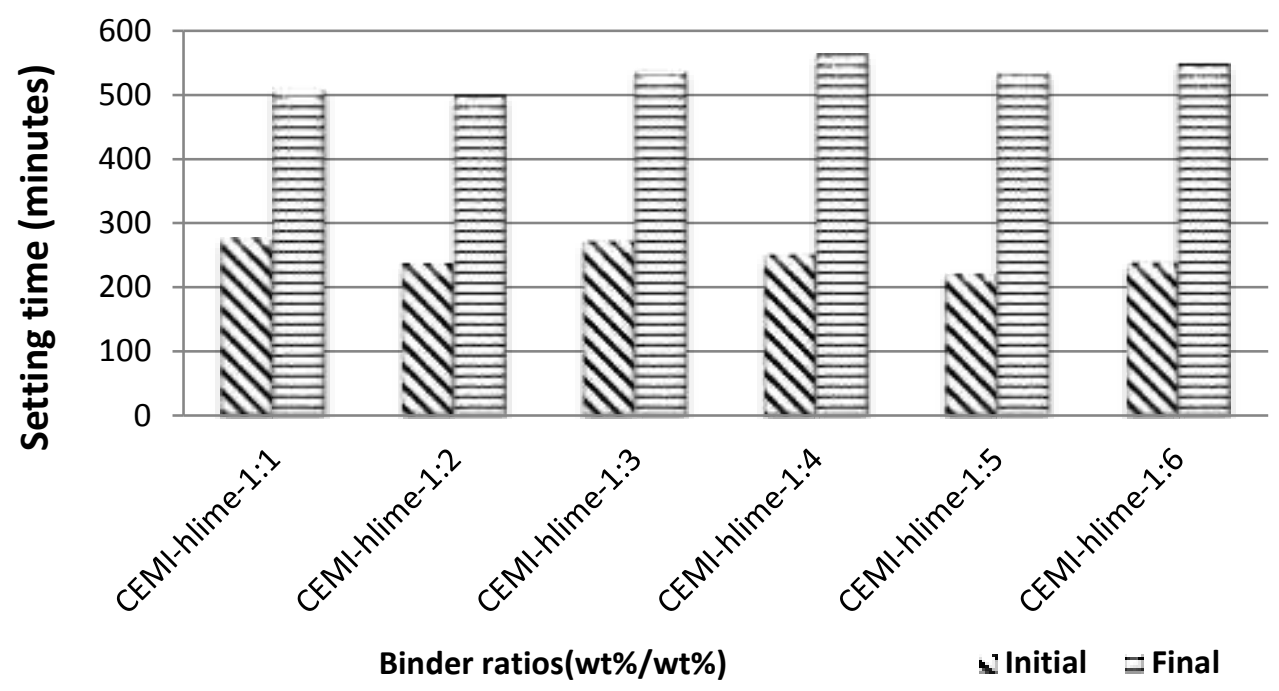

Figure 21 CEMI-hlime 1:1-1:6

The effect of hlime addition on setting time 


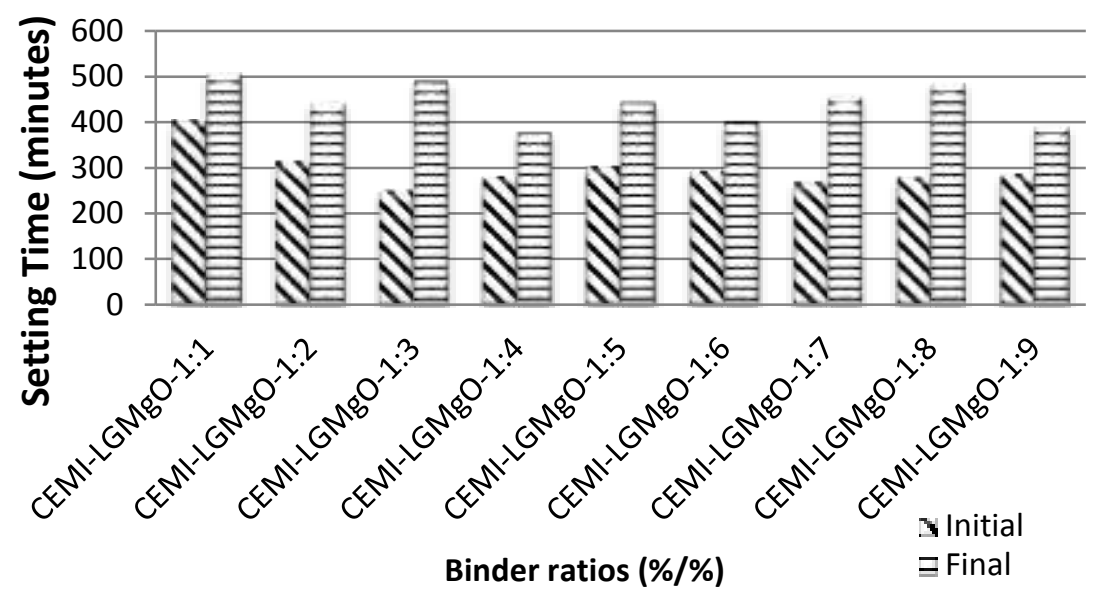

Figure 22 CEMI-LGMgO 1:1-1:9

The effect of LGMgO addition on setting time

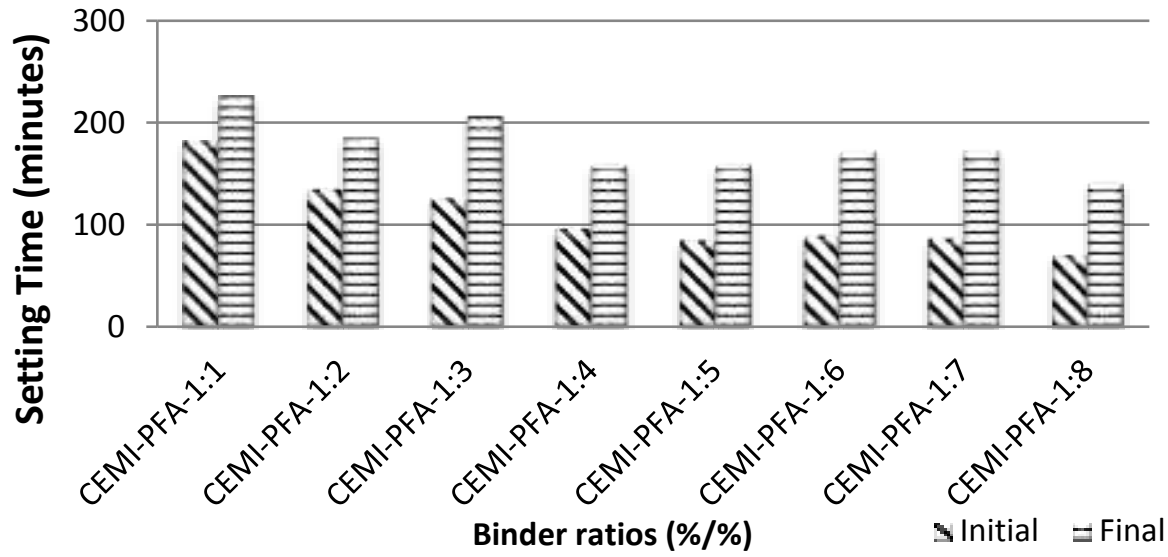

Figure 23 CEMI-PFA 1:1-1:9

The effect of PFA addition on setting time

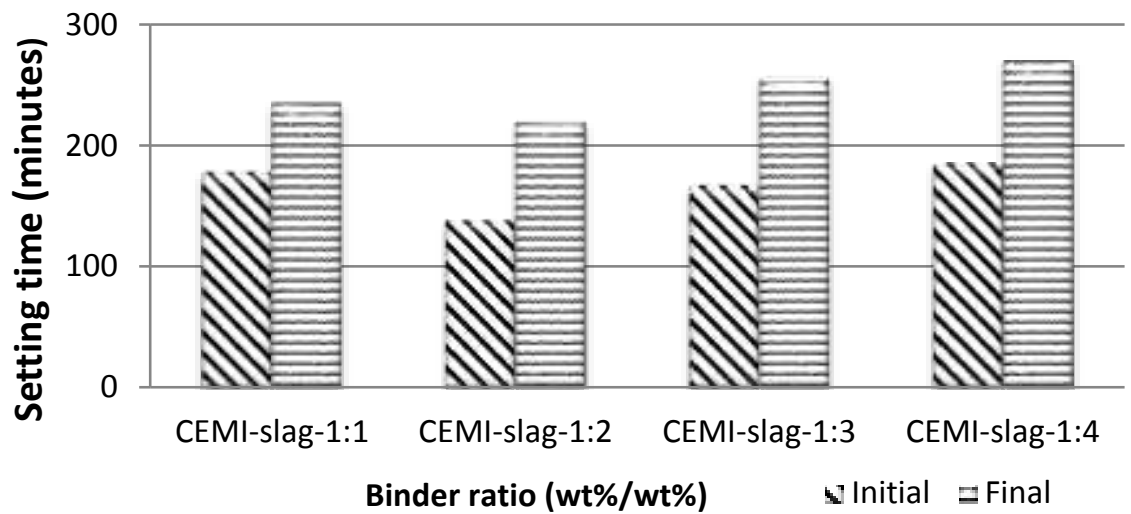

Figure 24 CEMI-slag 1:1-1:4

The effect of slag addition on the setting time

\subsection{Chemical Characteristics of Solidified Products}

\subsubsection{Acid Neutralisation Capacity (ANC)}

Based on the UCS, consistency and setting time results, the ratios to be used in the Stage 2 of this research study are $1: 2$ and 1:4. Hence, ANC testing was performed only on a selection of mixed design ratios and the results are illustrated in Figs. 25 to 33. As Fig. 25 shows, the pH results for CEMI-only mix design along with acid additions ranged from 4.71 to 12.62 . The graph shows a decreasing trend with the increase of acid additions. The $\mathrm{pH}$ of the mix design was around 6 at $8 \mathrm{meq} / \mathrm{g}$ acid additions, which means that the solution lost its alkalinity only with $8 \mathrm{meq} / \mathrm{g}$ or more acid addition levels. PC is an alkaline material that keeps the $\mathrm{pH}$ level of the environment basic in nature, even in the worst conditions where most of the materials could be kept insoluble. This 
is mainly the reason why PC has been accepted as a good fixation agent for heavy metals in S/S treatment technology. PC has a very high buffering capacity and is resistant to acid attacks.

As shown in Figs. 26 and 27, some pH data are missing. During the experimental study hlime-blended mixtures were found to have achieved a slightly decreasing trend with an increase in acid additions. Hence, there was no need to take $\mathrm{pH}$ readings between the values. Overall, it is apparent that regardless of the curing age, $\mathrm{pH}$ values decreased with acid additions although they were still at levels that are considered to be alkaline in nature. Hence, it is clear that hlime is an alkaline stabilising agent and does not lose this characteristic even under the worst conditions. $\mathrm{pH}$ values do not change significantly with further addition of hlime into the mixture. Moreover, no clear effect of curing on $\mathrm{pH}$ was observed at any point investigated. $\mathrm{pH}$ values were around 11.2 to 12.5, which is high enough to be considered alkaline even at very high level of acid additions.

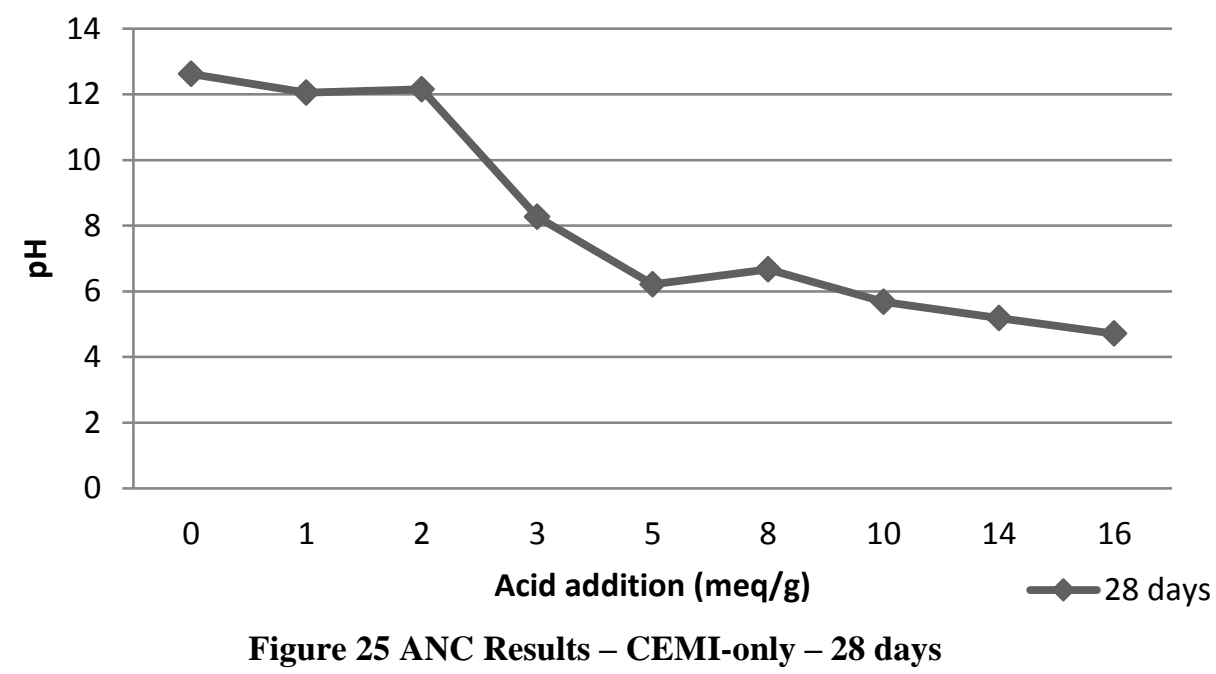

Figs. 28 and 29 illustrate the ANC results for CEMI-LGMgO at 7 and 28 days curing age, respectively. LGMgO blends demonstrated a very good buffering capacity even at high acid additions similar to PC and hlime blends. The $\mathrm{pH}$ values decreased to 7 with $7 \mathrm{meq} / \mathrm{g}$ or more acid additions. Figs. 30 and 31 show the ANC results for selected PFA-blended mixes at both 7 and 28 days curing age, respectively. The results indicate that PFA lowers $\mathrm{pH}$ values immediately when in contact with acid. Hence, the alkalinity cannot be preserved after $5 \mathrm{meq} / \mathrm{g}$ acid additions. Figs. 32 and 33 show the ANC results for CEMI-slag at 7 and 28 days curing age, respectively. The $\mathrm{pH}$ values were lower than 7 after $7 \mathrm{meq} / \mathrm{g}$ or more acid additions. Steel slag may also be considered as an alkaline material since it also resists acid attacks and remains in an alkaline condition even with high acid additions.

The ANC results of the as received materials used in the study are shown in Fig. 34. PC is an alkaline material and its buffering capacity is high as $\mathrm{pH}$ starts significantly decreasing only at $10 \mathrm{meq} / \mathrm{g}$ acid additions. On the other hand, as shown in Fig. 34, PFA is not resistant to acid attacks as its buffering capacity is very low. The $\mathrm{pH}$ levels of PFA decrease very sharply starting from 1 $\mathrm{meq} / \mathrm{g}$ acid addition down to 2.37 only at $1 \mathrm{meq} / \mathrm{g}$ acid addition. Steel slag, LGMgO and hlime are all alkaline materials and pH levels remain very high even at very high acid addition levels. The buffering capacity of these materials is extremely high and they are thus resistant to extreme acid attacks.

The $\mathrm{pH}$ levels of EAFD waste decrease very sharply at $7 \mathrm{meq} / \mathrm{g}$ acid addition, down to 3 . It may be concluded that if the stabilising agents used are alkaline materials with EAFD addition, the buffering capacity of the blended mixture should be reasonably high as EAFD resists acid attacks and $\mathrm{pH}$ levels would go down to acidic levels only with 7 or more meq/g acid additions. The buffering capacities of the binders are in the order, hlime > CEMI > slag > LGMgO $>$ PFA.
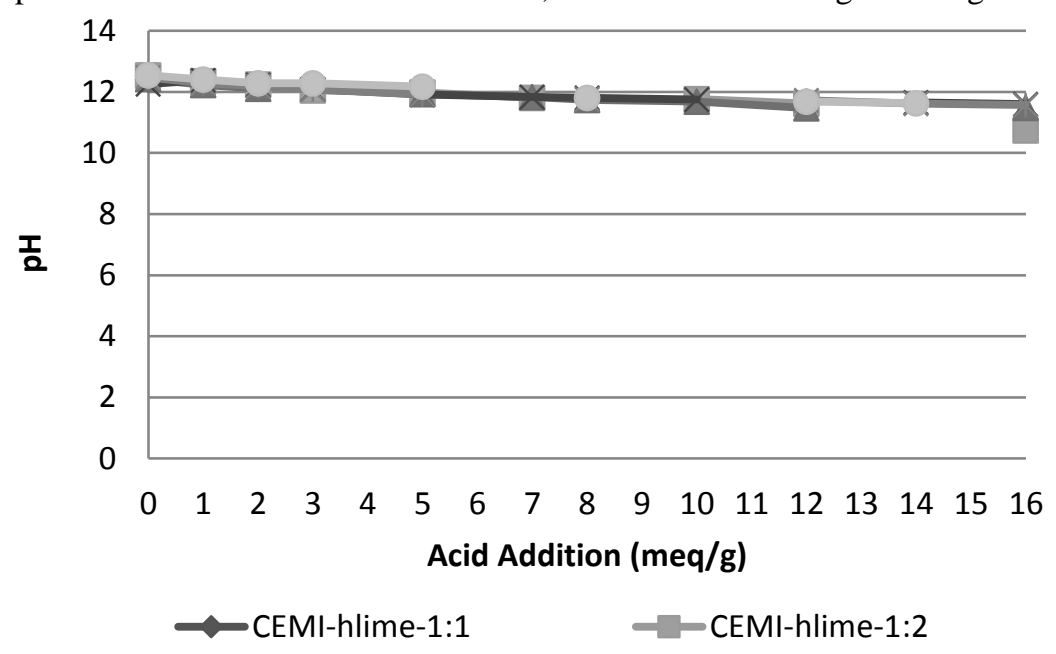

- CEMI-hlime-1:2

$\rightarrow$ CEMI-hlime-1:3

$\nVdash$ CEMI-hlime-1:4

Figure 26 ANC Results CEMI-hlime 1:1-1:6 - 7 days 


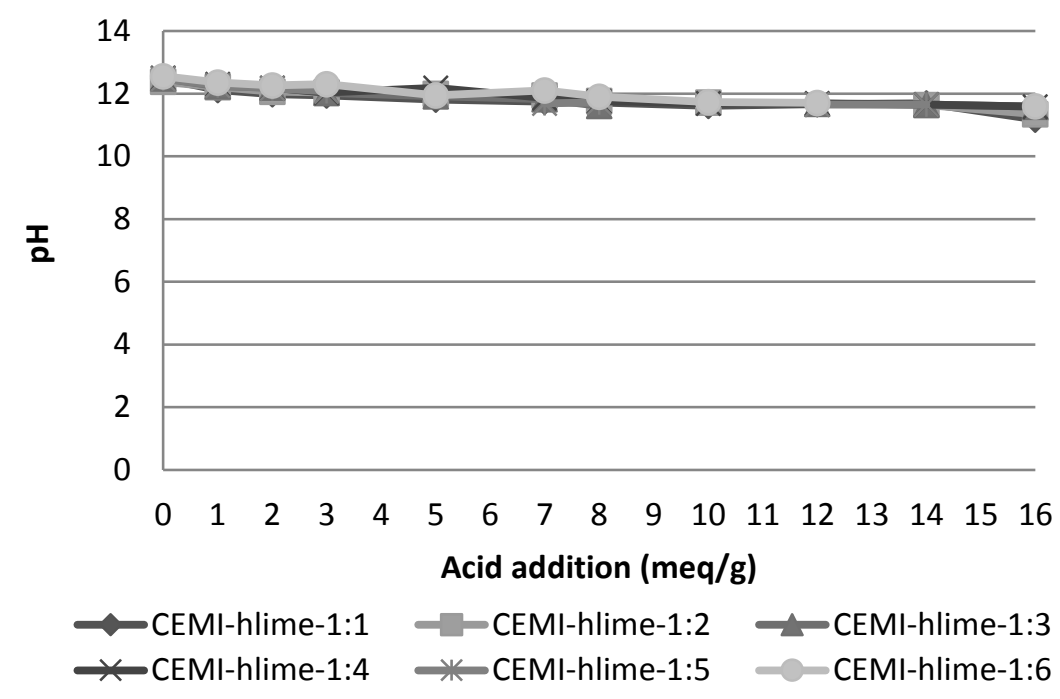

Figure 27 ANC Results CEMI-hlime 1:1-1:6 - 28 days

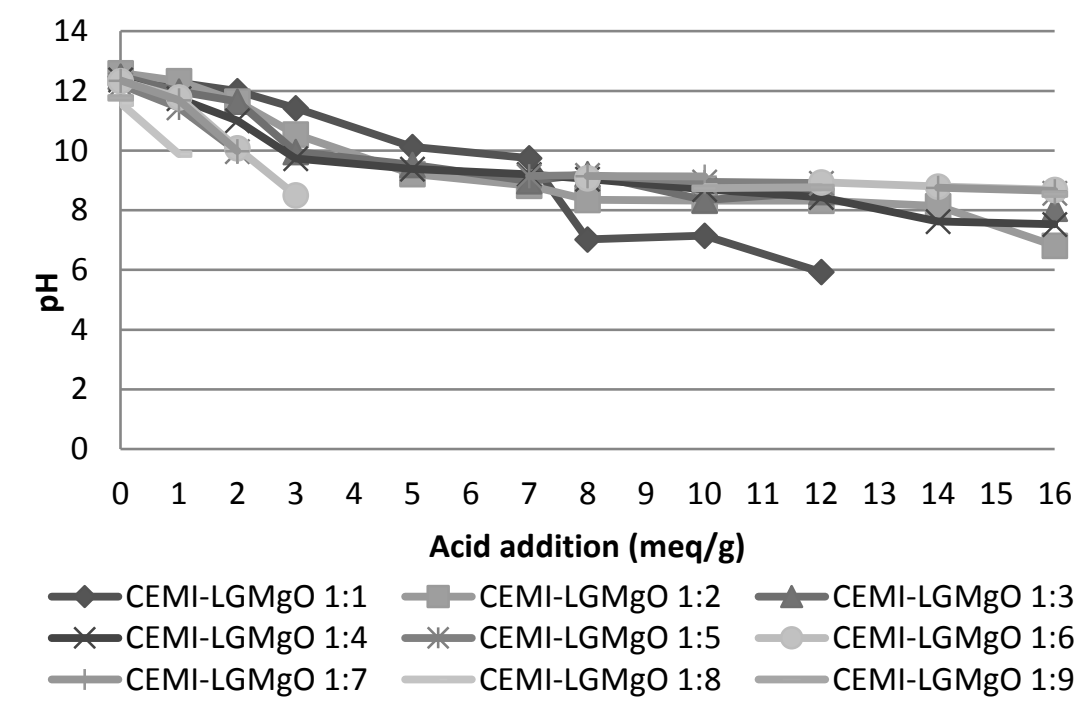

Figure 28 ANC Results CEMI-LGMgO 1:1-1:9 - 7 days

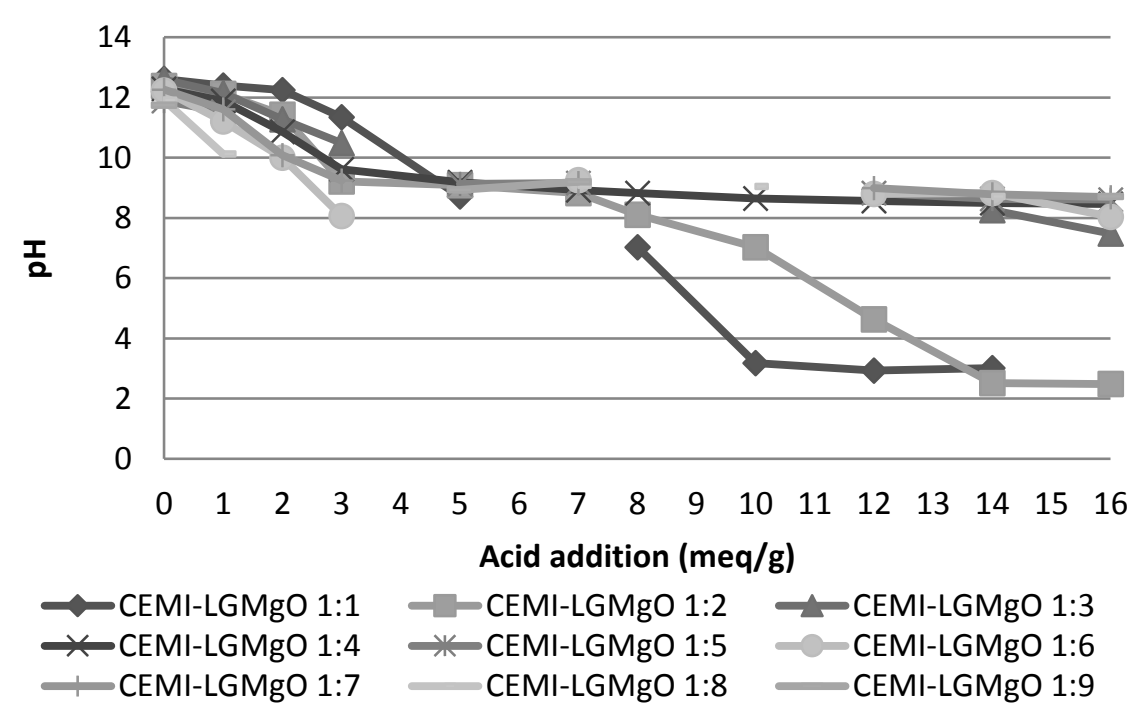

Figure 29 ANC Results CEMI-LGMgO 1:1-1:9 - 28 days 


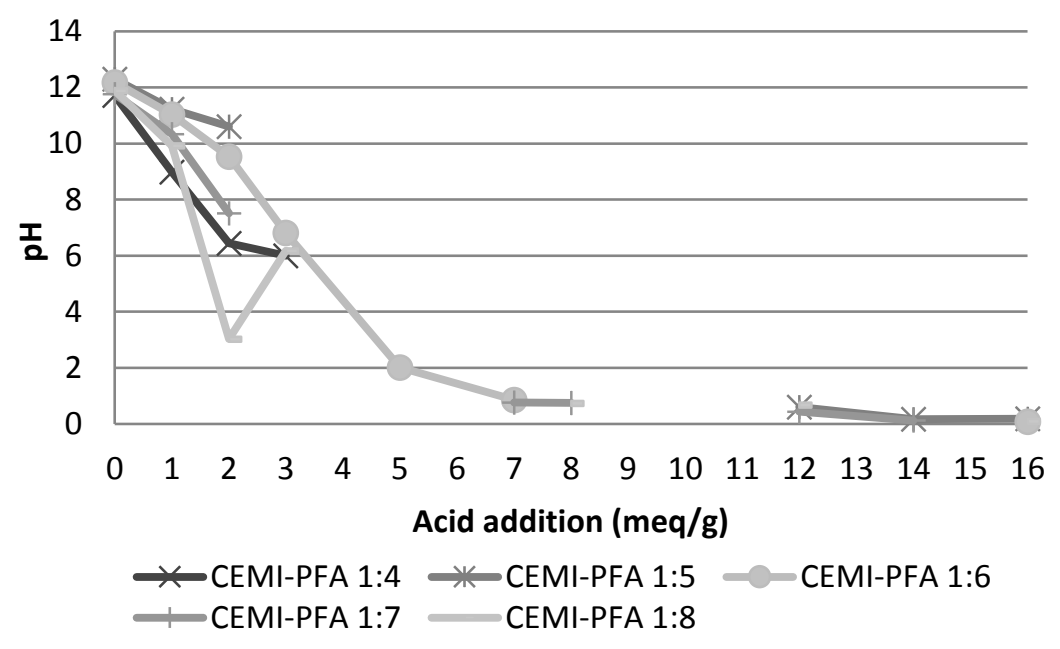

Figure 30 ANC Results CEMI-PFA 1:4-1:8 - 7 days
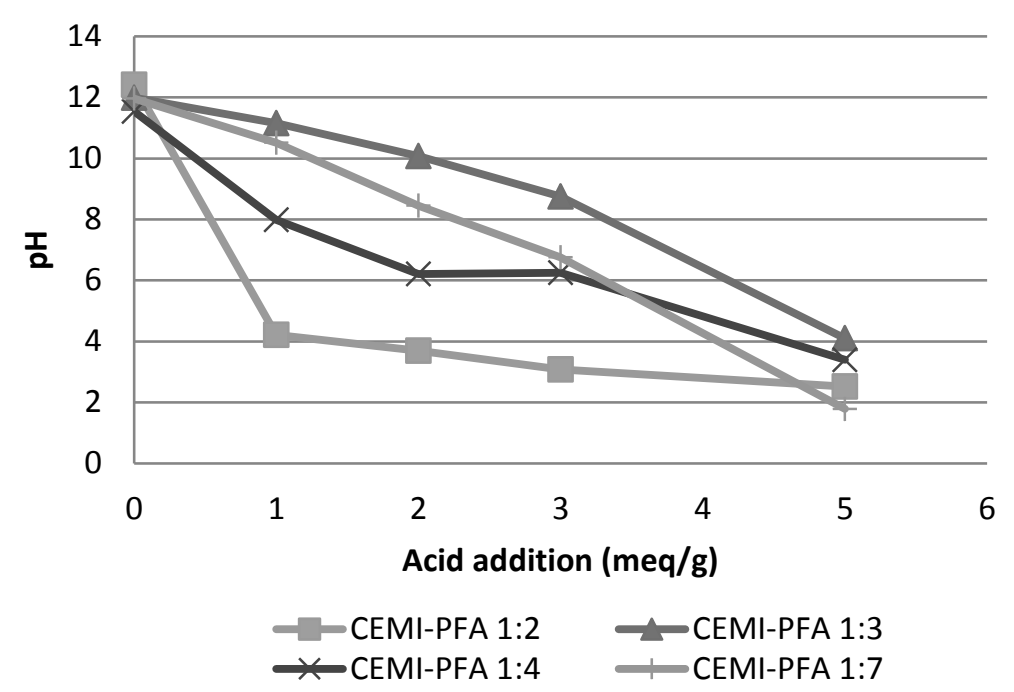

Figure 31 ANC Results CEMI-PFA - 28 days

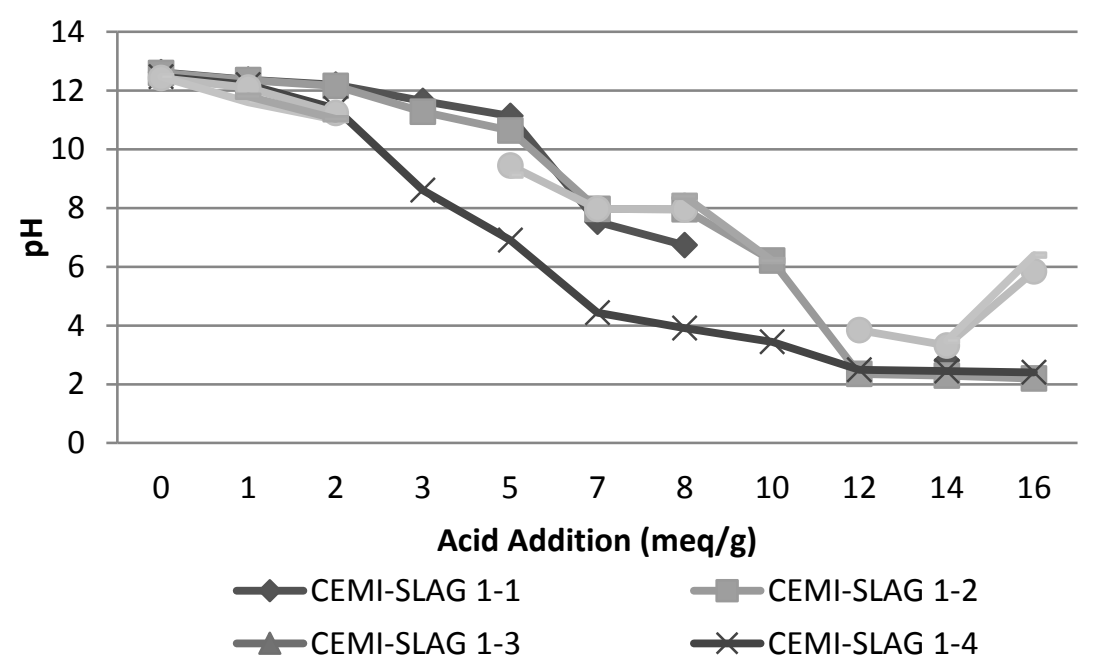

Figure 32 ANC Results CEMI-slag 1:1-1:9 - 7 days 


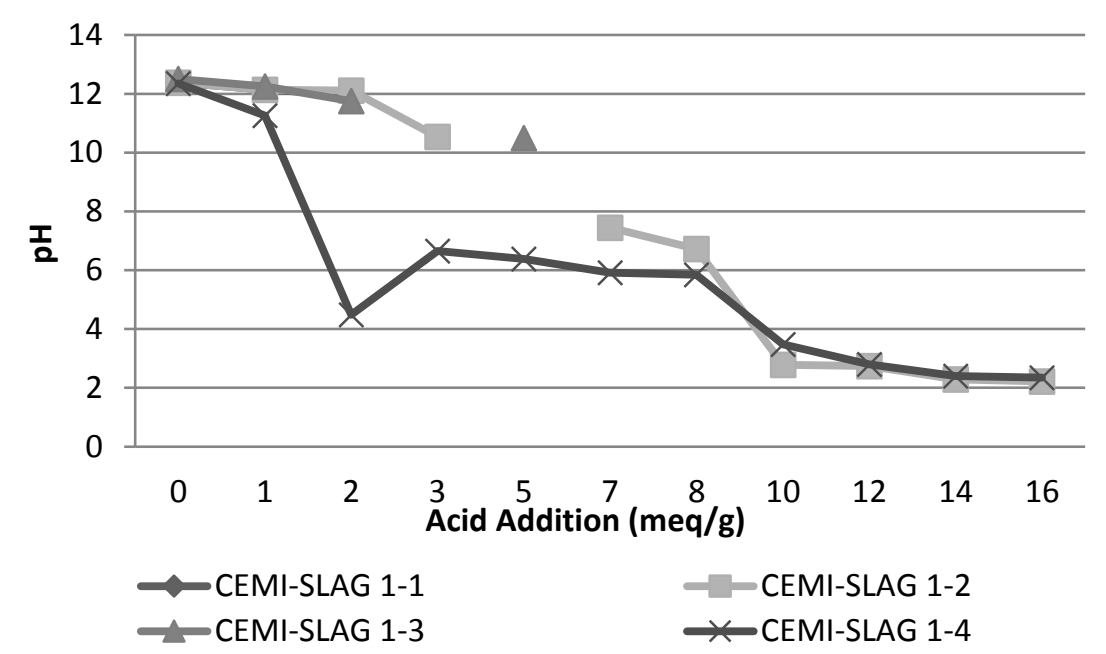

Figure 33 ANC Results CEMI-slag 1:1-1:4 - 28 days

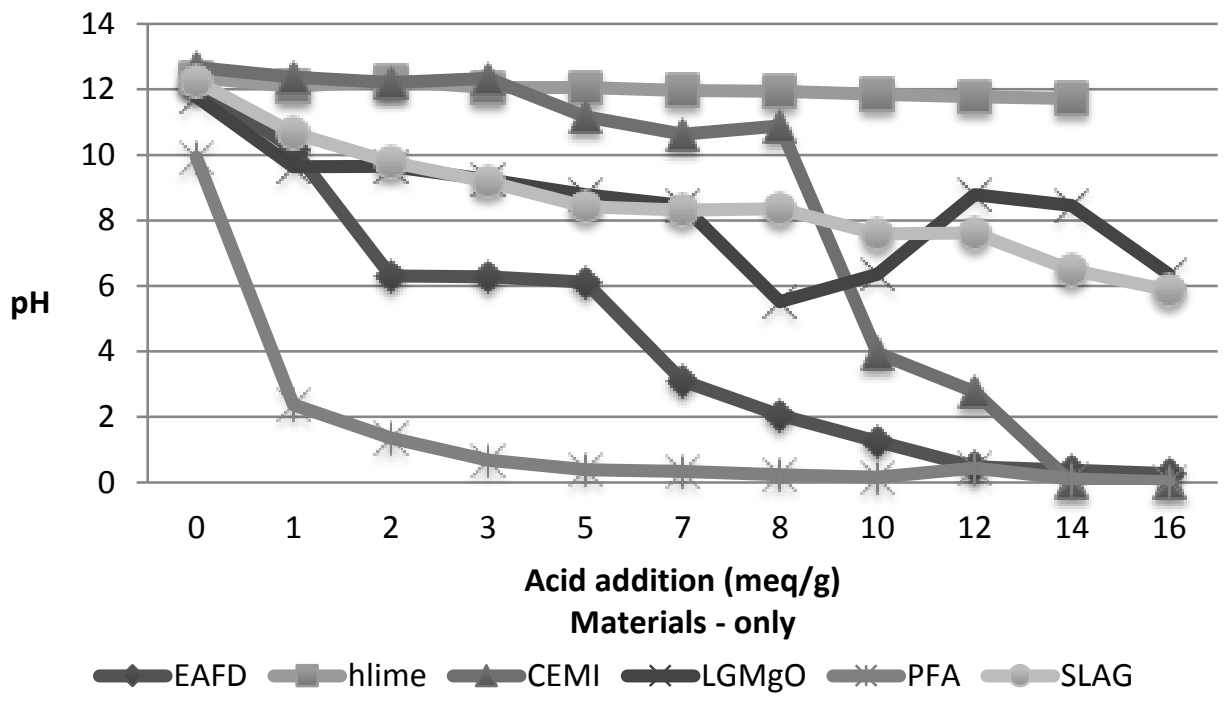

Figure 34 ANC Results for materials as received

\subsection{Leaching Test Results}

\subsubsection{Granular Leaching Test Results}

Heavy metal leaching is generally expected from materials which contain heavy metals in their as received state. After solidifying the samples, the leaching potential of heavy metals is tested and the influence of fixation on heavy metals leaching is examined. It is expected to see no heavy metals leaching at this point of testing. However, PFA, slag and LGMgO are by-products of some specific processes and hence they might contain some metals which may leach when in contact with the leaching medium. It is important to keep in mind that some reactions that occur during the mixing and interactions with water and hence the hydration may cause some metals that exist in very small quantities in the as received materials to leach. Leaching tests were therefore conducted on samples for validation purposes only. The granular leaching test results obtained are shown in Tables 13 to 16 . No heavy metal leaching was observed at any ratios and mix designs studied at 28 days of curing age.

\subsubsection{Monolithic Leaching Test Results}

In Stage 1 of the experiments, only the heavy metals were investigated in the monolithic leaching tests. Tables 17 to 20 show the monolithic leaching test results for mix combinations. The results indicate that Ba leached and exceeded the WAC limits at some CEMI-hlime ratios whereas Mo leaching was observed in CEMI-PFA mix blends and both Mo and As leached from CEMIslag mix combinations with rates higher than the WAC leachability limits. Ba leaching is linked to the fact that it may be found in a relatively soluble form: $\mathrm{Ba}(\mathrm{OH})_{2}$. Cr leaching can only be controlled if it is reduced from the $\mathrm{Cr}(\mathrm{VI})$ to the $\mathrm{Cr}(\mathrm{III}) \mathrm{form}$ [28]. Mo may be in the form of $\mathrm{MoO}_{3}$ and dissolved in an alkaline solution. Ca content plays an important role in controlling As 
leachability. If the amount of lime is high in a system, it is more effective in lowering the leachability of As than PC. Therefore, a higher $\mathrm{Ca}$ content means lower As leaching rates. The formation of calcium arsenite $\left(\mathrm{CaHAsO}_{3}\right)$ reduces the leaching rate and mobility of As.

LGMgO and steel slag contain very small amounts of heavy metals as a result of the production process and hence the leaching of those elements is not very surprising when it comes to the cumulative leaching of metals in question. However, for CEMILGMgO mix combinations, none of the leaching rates of metals under discussion exceeded the limits at any ratio studied. This is probably due to the high alkalinity of the CEMI/LGMgO binder system and successful fixation of heavy metals within the S/S matrix.

\section{CONCLUSIONS}

- $\quad$ Best physical performances were achieved in the following order: CEMI-only > CEMI-slag > CEMI-PFA > CEMILGMgO > CEMI-hlime. However, most of the slag-blended samples achieved higher UCS values than CEMI-only samples at longer curing ages ( $\geq 28$ days, CEMI-slag 1:2:40, at 56 days, both CEMI-slag 1:2:70 and 1:4:40).

- Metals mobility of $\mathrm{Pb}, \mathrm{Cd}$ and $\mathrm{Zn}$, is associated with $\mathrm{pH}$. Low $\mathrm{pH}$ values $(<7)$ increase the solubility of the metals in question, whereas $\mathrm{pH}$ values in the range of 8 to 11 decreases the mobility of those metals.

- The leaching test results showed that the leaching test according to [9] provides a more conservative scenario than the one presented by the standard [29] for granular waste.

- Effective replacement of cement by LGMgO and steel slag (both waste by-products) at a ratio of 1:4 significantly improves both the economics and sustainability characteristics of cement replacement.

\section{Recommendations And Future Work}

Matrix integrity is important for maintaining the low permeability of the system and the insolubility of the metals encapsulated in the solid matrix. The physical integrity of the matrix could be deteriorated by its dissolution; therefore, maintaining low bulk matrix solubility is required [20]. The leachability of the metals could only be controlled by diffusion and hence the leaching mechanism of each metal in the matrix should be known in order to have control over the contaminants' mobility. Therefore, diffusion leaching mechanism assessment is required to determine the mechanisms that control the leaching of the heavy metals in the matrix.

Contaminants transported into the environment by diffusion must first be dissolved in the pore water and hence the $\mathrm{pH}$ condition of the pore water is important to control the metals' solubility in order to reduce the diffusion of the contaminants into the environment. Therefore, it is important to determine the leaching mechanisms that control the metals leaching in both the early and later intervals.

\section{References}

1. Middendorf, B., Martirena, J. F., Gehrke, M., and Day, R. L. (2005) 'Lime pozzolan binders: An alternative to OPC'. International Building Lime Symposium Proceedings. 9-11 March. Orlando, FL.

2. Gutt, W. (1971) Manufacture of cement from industrial by-products. Garston, England: Building Research Station.

3. Tsakiridis, P. E., Papadimitriou, G. D., Tsivilis, S., and Koroneos, C. (2008) 'Utilization of steel slag for Portland cement clinker production', Journal of Hazardous Materials, 152, pp. 805-811.

4. Conner, J. R. and Hoeffner, S. L. (1998b) 'The history of Stabilisation/solidification technology', Critical Reviews in Environmental Science and Technology, 28(4), pp. 325-396.

5. American Society for Testing and Materials (ASTM) (1989a) ASTM C 150-89 - Standard specification for Portland cement. Philadelphia, PA: ASTM (replaced by ASTM C 618-12 in 2012).

6. American Society for Testing and Materials (ASTM) (1989b) ASTM C 618-89 - Standard specification for fly ash and raw - or calcinate natural pozzolans for use as a mineral admixture in Portland cement concrete. Philadelphia, PA: ASTM (replaced by ASTM C150/150M-12 in 2012).

7. Conner, J. R. (1990) Chemical Fixation and Solidification of Hazardous Wastes. New York: Van Nostrand Reinhold.

8. British Standards Institution (2001) BS EN 459-1:2001 Building Lime: Definitions, Specifications and Conformity Criteria. London: BSI, replaced by BS EN 459-1:2010.

9. Environment Agency (2004) EA NEN 7375:2004 Leaching Characteristics of Moulded or Monolithic Building and Waste Materials. Determination of Leaching of Inorganic Components with the Diffusion Test. 'The tank test' Based on the translation of the Netherlands Normalisation Institute Standard, Version 1.0, Environment Agency, UK.

10. Shi, C., Stegemann, J. A., Caldwell, R. J. (1997) 'An examination of interference in waste solidification through measurement of heat signature', Waste Management, 17(4), pp. 249-255. 
11. Skvara, F., Kastanek, F., Pavelkova, I., Solvoca, O., Maleterova, Y., and Schneider, P. (2002) 'Solidification of waste steel foundry dust with Portland cement', Journal of Hazardous Materials, 89, pp. 67-81.

12. De Vargas, A. S., Masuero, A. ., and Vilela, A. C. F. (2006) 'Investigations on the use of electric-arc furnace dust (EAFD) in pozzolan-modified Portland cement I (MP) pastes', Cement and Concrete Research, 36, pp. 1833-1841.

13. Andres, A. and Irabien, J.A. (1994b) 'The influence of binder/waste ratio on leaching characteristics of solidified/stabilized steel foundry dusts', Environmental Technology, 15, pp. 343-351.

14. Bayuaji R., Kurniawan R.W., Yasin A.K., Fatoni HAT, Lutfi FMA, The effect of fly ash and coconut fibre ash as cement replacement materials on cement paste strength, International Conference on Innovation in Engineering and Vocational Education, Materials Science and Engineering, 128, 2016, IOP Publishing.

15. Stegemann, J. A. and Cote, P. L. (1996) 'A proposed protocol for evaluation of solidified wastes', Science of the Total Environment, 178, pp. 103-110.

16. Andres, A. and Irabien, J. A. (1994a) 'Solidification/stabilization process for steel foundry dust using cement-based binders: Influence of processing variables', Waste Management \& Research, 12, pp. 405-415.

17. Irabien, J. A., Fernandez-Olmo, I., Andres, A., and Sebastia, M. (2002) 'Prediction of TCLP leachates of electric arc furnace dust/cement products using neural network analysis', Environmental Progress, 21, pp. 95-104.

18. Fernandez, A. I., Chimenos, J. M., Raventos, N., Miralles, L., and Espiell, F. (2003) 'Stabilisation of electrical arc furnace dust with Low-grade MgO prior to landfill’, Journal of Environmental Engineering, 129, pp. 275-279.

19. Salihoglu, G., Pinarli, V., Salihoglu, N. K., and Karaca, G. (2007) 'Properties of steel foundry electric arc furnace dust solidified/stabilized with Portland cement', Journal of Environmental Management, 85, pp. 190-197.

20. Stegemann, J. A. and Zhou, Q. (2009) 'Screening tests for assessing treatability of inorganic industrial wastes by stabilisation/solidification with cement', Journal of Hazardous Materials, 161, pp. 300-306.

21. Lim, S., Jeon, W., Lee, L., Lee, K., and Kim, N. (2002) 'Engineering properties of water/wastewater-treatment sludge modified by hydrated lime, fly ash and loess', Water Research, 36(17), pp. 4177-4184.

22. Oner, A. and Akyuz, S. (2007) 'An experimental study on optimum usage of GGBS for the compressive strength of concrete', Cement and Concrete Composites, 29, pp. 505-514.

23. Boutouil, M. and Levacher, D. (2005) 'Effect of high initial water content on cement-based sludge solidification', Ground Improvement, 9, pp. 169-174.

24. Neville, A. M. (1995) Properties of Concrete, Essex: UK, Addison Wesley Longman Limited.

25. Maher A., Najm H., and Boile M. (2005) Solidification/Stabilization of Soft River Sediments Using Deep Soil Mixing. Washington, DC: U.S. Department of Transportation.

26. Mehta, P. K. (1989) 'Pozzolanic and cementitious by-products in concrete - another look'. Proceedings of the $3^{\text {rd }}$ International Conference on Fly Ash, Silica Fume, Natural Pozzolans in Concrete. Trondheim, Norway, pp. 1-43.

27. Bijen, J. and Niël, E. (1981) 'Supersulphated cement from blast furnace slag and chemical gypsum available in the Netherlands and neighbouring countries', Cement and Concrete Research, 11, pp. 307-322.

28. Dermatas, D. and Moon, D. H. (2006) 'Chromium leaching and immobilization in treated soils', Environmental Engineering Science, 23(1), pp. 77-87.

29. British Standards Institution (2002) BS EN 12457-3:2002, Characterisation of Waste. Leaching. Compliance Test for Leaching of Granular Waste Materials and Sludges. London: BSI. 